\title{
The supramolecular redox functions of metallomacromolecules
}

\author{
Didier Astruc(D)
}

\begin{abstract}
Metallomacromolecules are frequently encountered in redox proteins including metal-tanned hide collagen and play crucial roles involving supramolecular properties in biological electron-transfer processes. They are also currently found in non-natural families, such as: metallopolymers, metallodendrimers and metallodendronic polymers. This mini-review discusses the supramolecular redox functions of such nanomaterials developed in our research group. Electron-transfer processes are first examined in mono-, bis- and hexa-nuclear ferrocenes and other electron-reservoir organoiron systems showing the influence of supramolecular and reorganization aspects on their mechanism. Then applications of electron-transfer processes using these same organoiron redox systems in metallomacromolecules and their supramolecular functions are discussed including redox recognition/sensing, catalysis templates, electrocatalysis, redox catalysis, molecular machines, electrochromes, drug delivery device and nanobatteries.

Keywords: Ferrocene, electron reservoir, Polymer, Dendrimer, Redox catalyst, Redox sensor, Molecular machine, Supramolecular template, Electrochrome, Drug delivery device, Battery
\end{abstract}

\section{Introduction}

The supramolecular redox functions of metallomacromolecules are ubiquitous in the chemistry of life [1] as exemplified by electron transfers in metalloproteins [2], the role of ferredoxins achieving electron transfers in many redox reactions of the metabolism including photosynthesis [3] and nitrogenase [4], and a number of other biocatalytic redox processes of metalloenzymes [5]. Nature has also inspired chemists for the mimicry of biological redox processes in modern technology, for instance in the fields of energy [6,7], nanomedicine [8], and the metal-tanning process of leather industry [9]. The designs of redox reagents mimicking the redox sites of metalloenzymes range from metalloporphyrins [10] that are found as redox site of oxidoreductase enzymes such cytochromes that are involved in many crucial functions, metallophthalocyanins $[11]$ found in

Correspondence: didier.astruc@u-bordeaux.fr

Dedicated to our distinguished colleague and friend Professor Wuyong Chen (University of Sichuan, Chengdu) at the occasion of his 68th birthday.

ISM, UMR CNRS 5255, Univ. Bordeaux, 351 Cours de la Libération, 33405

Talence Cedex, France pigments, clusters found in ferredoxins and other metallocyclic nitrogen ligands such as corrolle found in vitamin $B_{12}$ [1]. Interestingly non-biological redox reagent using metals and ligands that are not found in living system can also achieve remarkable performances, such as polypyridyl-noble metal complexes that are useful in photophysical processes, organic synthesis [12] and polyphenol-metal (e.g. $\mathrm{Al}^{\mathrm{III}}, \mathrm{Cr}^{\mathrm{III}}$ ) complexes that are powerful tanning system to improve the hydrothermal stability of tanned leather [9]. Another well-known and current family of non-natural redox systems that could be rationalized and optimized regarding its usefulness is that of the late transition-metal sandwich complexes [13]. This later area has concentrated our attention during several decades and will be discussed in this minireview essentially based on research conducted in our laboratories. When these non-natural redox systems are engaged in macromolecular materials, their redox switch can exert a variety of functions and processes that are used in synthesis, catalysis, biomedicine and materials science [14]. In biological as well as non-natural processes, the supramolecular aspects involving the redox

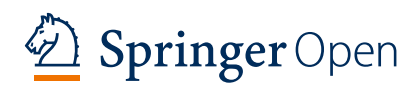

(c) The Author(s). 2020 Open Access This article is licensed under a Creative Commons Attribution 4.0 International License, which permits use, sharing, adaptation, distribution and reproduction in any medium or format, as long as you give appropriate credit to the original author(s) and the source, provide a link to the Creative Commons licence, and indicate if changes were made. The images or other third party material in this article are included in the article's Creative Commons licence, unless indicated otherwise in a credit line to the material. If material is not included in the article's Creative Commons licence and your intended use is not permitted by statutory regulation or exceeds the permitted use, you will need to obtain permission directly from the copyright holder. To view a copy of this licence, visit http://creativecommons.org/licenses/by/4.0/. 
centers and their close ligand environment play a particularly crucial role due to the hydrogen bonds, electrostatic interaction and redox-induced structural and conformational changes in these metallomacromolecules [15].

\section{Electron transfer by Electron-rich Organo-Iron Sandwich complexes}

The stabilities of the redox states of a redox reagent within a given timescale are a fundamental criterium toward functions. This story started with the discovery of ferrocene in the late 1940's and early 1950's, mainly by Fischer, Wilkinson and Woodward [16], that boosted a number of disciplines including organotransition-metal chemistry, homogeneous catalysis and materials science [17]. In the early days of organotransition-metal chemistry, research on single electron-transfer aspects and their subsequent chemistry was not privileged besides electrochemical studies $[18,19]$. In the early days, redox changes were found to be central in transition-metal chemistry, however, as illustrated by Taube when he classified ligand-substitution reactions as a function of the metal oxidation state $[20,21]$. In ferrocene chemistry, the oxidation of the parent ferrocene and its alkylsubstituted derivatives is straightforward in a region of potentials that are readily accessible with a large choice of oxidizing reagents and at a convenient oxidation potential around $+0.4 \mathrm{~V}$ vs. saturated calomel electrode (SCE) in organic solvents such as THF, 1,2-dichloromethane, and acetonitrile [22]. Under these conditions, the isolation of the oxidized form of ferrocene, ferricenium ( $\mathrm{a} \mathrm{d}^{5} \mathrm{Fe}(\mathrm{III})$, 17-electron complex), is relatively easy using tetrafluoroborate $\left(\mathrm{BF}_{4}^{-}\right)$or hexafluorophosphate $\left(\mathrm{PF}_{6}{ }^{-}\right)$as a counter-anion. In turn, the latter salts can be used as mild single-electron oxidants [23]. Due to the absence of an electron in a bonding orbital [24] and the positive charge, however, this cation is somewhat fragile in solution especially in polar solvents, and the situation becomes even more complicated when a ferrocene ring bears an electron-withdrawing substituent such as an acyl group due to the anodic shift of the redox potential and the decreased stability of the oxidized form [25]. On the cathodic side, reduction of ferrocene itself has been observed by cyclic voltammetry, but the cathodic potential is so negative $(-3 \mathrm{~V}$ vs. SCE) that the isolation of the ferrocene $\mathrm{Fe}(\mathrm{I})$ anion is too difficult and has never been obtained [26].

In 1979, the seminal finding for the first time of the stable and isolable $\mathrm{Fe}(\mathrm{I})$ state in a large family of monomeric iron (I) sandwich complexes [27] stable under two or three oxidation states (Scheme 1) opened the possibility of a cascade of stoichiometric and catalytic electrontransfer reactions involving a variety of organic and inorganic substrates, demonstrating the remarkable usefulness of this new family of complexes that were called "Electron Reservoirs" [28-32].

The $\mathrm{Cp}^{*}$ series $\left(\mathrm{Cp}^{*}=\eta^{5}-\mathrm{C}_{5} \mathrm{Me}_{5}\right)$ are also known in both families of complexes and present even more robust redox systems as electron reservoirs $[17,21,23,29$, 33] that have been integrated in polymers and dendrimers (see text).

Neutral $\mathrm{Fe}(\mathrm{I})$ sandwich complexes, such as $\mathrm{CpFe}^{\mathrm{I}}\left(\eta^{6}\right.$ $\left.\mathrm{C}_{6} \mathrm{Me}_{6}\right)$, I, and $\mathrm{Cp}^{*} \mathrm{Fe}^{\mathrm{I}}\left(\eta^{6}-\mathrm{C}_{6} \mathrm{Me}_{6}\right)$ in which $\mathrm{Cp}=\eta^{5}-\mathrm{C}_{5} \mathrm{H}_{5}$ and $\mathrm{Cp}^{*}=\eta^{5}-\mathrm{C}_{5} \mathrm{Me}_{5}$ [33] that are Jahn-Teller active [34] have indeed been found by $\mathrm{He}(\mathrm{I})$ photoelectron spectroscopy to be the most electron-rich known neutral molecules and remain so to-date based on the extremely low values of their ionization potentials [35]. These complexes are excellent initiators of electron-transfer-chain reactions [36, 37] and redox catalysts for the reduction of nitrate and nitrites to ammonia [38, 39]. Interestingly, they react very fast with $\mathrm{O}_{2}$ or air even under subambient conditions. For instance, the forest-green prototype complex I provides an extremely mild $\mathrm{C}-\mathrm{H}$ activation upon such a simple contact with $\mathrm{O}_{2}$ yielding the red ferrocene-like cyclohexadienylidene Fe (II) derivative. The superoxide radical anion was detected by its characteristic EPR spectrum as a reaction intermediate. Its formation is due to fast exergonic electron transfer from $\mathrm{Fe}(\mathrm{I})$ to $\mathrm{O}_{2}$ leading to a contact ion pair [Fe(II) ${ }^{+}$, $\mathrm{O}_{2}{ }^{-}$] in which benzylic deprotonation by superoxide anion activated by the positive charge on the sandwich compound is also fast even at very low temperature. The nucleophilic reactivity of the cyclohexadienylidene complex is very rich and useful, forming a variety of bonds upon reactions with many electrophiles [39, 40]. The complexes $\left[\mathrm{C}_{5} \mathrm{R}_{5} \mathrm{Fe}\left(\eta^{6}-\mathrm{C}_{6} \mathrm{Me}_{6}\right)\right]^{\mathrm{x}+}$ were isolated in the three oxidation states $(\mathrm{x}=0-2)$ corresponding to Fe(II,I, $0)$, and electron-transfer interplay involving various substrates were demonstrated [41]. In addition, the structure-reactivity relationships, established with the family of mixed sandwich complexes $\mathrm{C}_{5} \mathrm{R}_{5} \mathrm{Fe}\left(\eta^{6}-\mathrm{C}_{6} \mathrm{Me}_{6}\right)$, $\mathrm{R}=\mathrm{H}$ or $\mathrm{Me}$, have been generalized to first-row late transition metal sandwich complexes for which the neutral forms have 19- or 20 valence electrons, as for instance to the 19-electron cobaltocene derivatives $\left[\left(\eta^{5}\right.\right.$ $\left.\left.\mathrm{C}_{5} \mathrm{R}_{5}\right) \mathrm{Co}\left(\eta^{5}-\mathrm{C}_{5} \mathrm{R}_{5}^{\prime}\right)\right]\left(\mathrm{R}, \mathrm{R}^{\prime}=\mathrm{H}\right.$ or $\left.\mathrm{Me}\right)$ [42] and the 20electron complex $\left[\mathrm{Fe}\left(\eta^{6}-\mathrm{C}_{6} \mathrm{Me}_{6}\right)_{2}, \quad[43]\right]$. Even main group hydrides such as $\mathrm{NaBH}_{4}$ and $\mathrm{LiAlH}_{4}$ can behave as electron-reservoirs able to transfer an electron to substrates at a very negative potential [44-46]. Among the useful electron-transfer reactions of these neutral 19electron complexes, a recently conducted one is remarkable: the reduction of a variety of commercial late transition metal salts quickly leading to very small metal nanoparticles [47-49], whereas for instance $\mathrm{NaBH}_{4}$ often produces transition metal borides [50]. Under these 


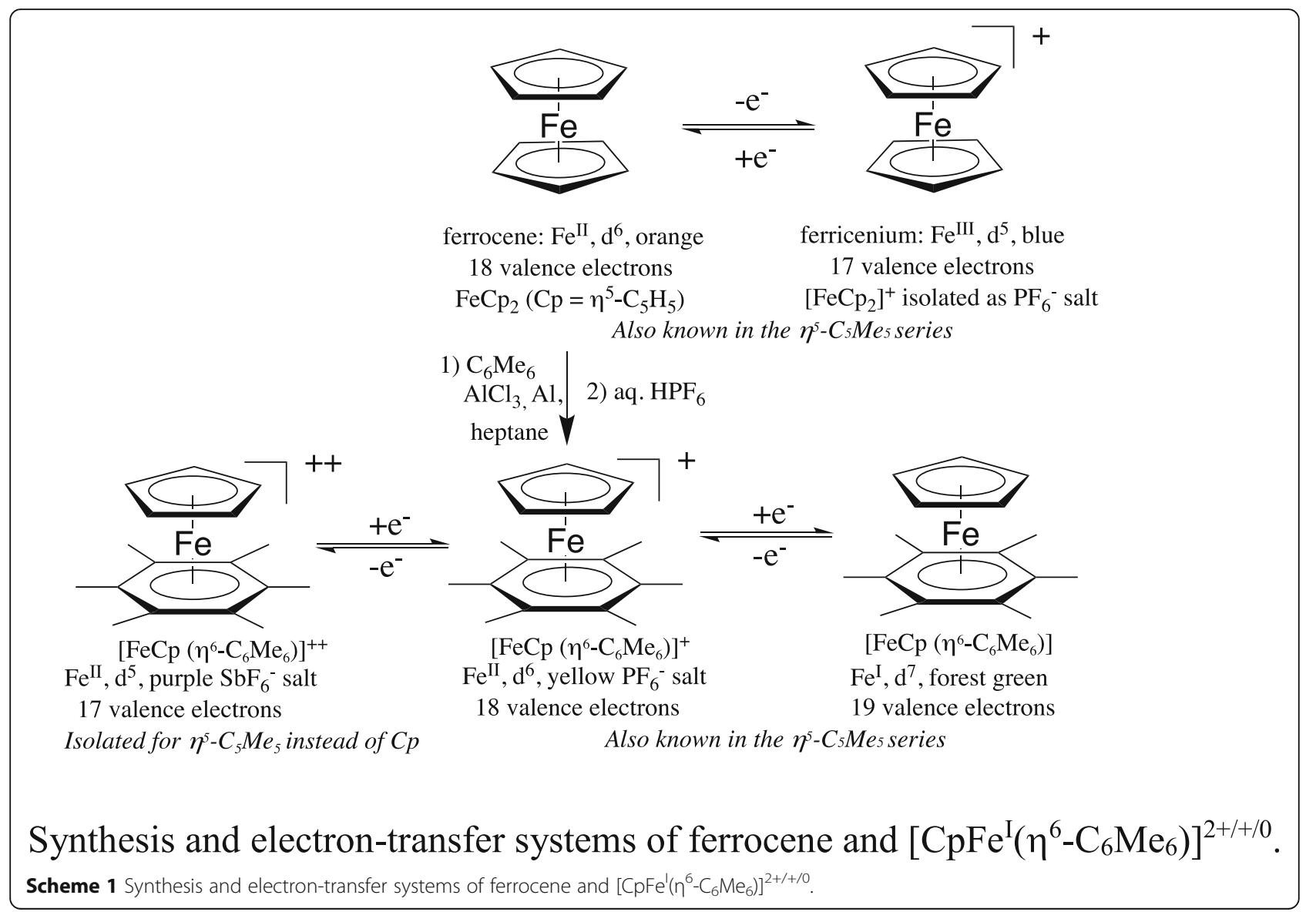

conditions the driving force of the reactions is high given the very negative value of the oxidation potential of the neutral 19-electron complexes, resulting in the formation of very small nanoparticles whose catalytic activities are all the higher as they are clean and smaller [47-49]. This catalytic activity compares with that obtained using, for the reduction of these salts, the very strong reductant naphthalene anion that is much less easy to manipulate and quantify in stoichiometric amounts [51].

\section{From single to simultaneous multi-Electron transfer}

A key issue in electron-transfer reactions is the possibility to transfer two or several electrons simultaneously, because such multi-electron transfers are required in most biological energy-related processes [1]. Nature offers a variety of multi-electron transfer catalysts as for instance in photosynthesis [52], nitrogen reduction [53], etc., and unnatural catalysts are designed to mimic $\mathrm{Na}-$ ture in some way as for instance towards water oxidation catalysts [54] and lithium-ion batteries [55]. Thus, it is of interest to examine how multi-electron transfer system may proceed in molecular and solid-state systems
[56]. In molecular systems, electrochemical oxidation or reduction of single or multi-redox site systems transfers one electron at a time (to or from the electrode at least for both statistical and electrostatic reasons [57], which brings about a difficult challenge in the design of bi- or polyelectron transfer systems. Cascades of singleelectron transfers are currently found in cluster/nanoparticle electrochemistry. With single redox centers see, e.g. the hexanethiol-capped $\mathrm{Au}_{147}$ nanocluster showing 15 high-resolution quantized double-layer charging peaks $[58,59]$, and with two redox centers see e.g. binuclear transition-metal sandwich complexes displaying a cascade of 4 reversible monoelectronic waves from $\mathrm{Fe}(\mathrm{II})-\mathrm{Fe}(\mathrm{II})$ to $\mathrm{Fe}(0)-\mathrm{Fe}(0)$ in the example of the complex $\left[\mathrm{Fe}_{2}\left(\mu^{2}, \eta^{10}-\mathrm{C}_{10} \mathrm{H}_{8}\left(\mathrm{C}_{6} \mathrm{Me}_{6}\right)_{2}\right]^{\mathrm{n}+}, n=0-2\right.$ [60]. In simple related systems, however, it is possible to observe a two-electron wave between a dication and a neutral species. This is achieved if the redox reaction proceeds with a chemically reversible structural change occurring in the course of the second electron transfer and if the structural reorganization energy is larger than (thus compensates) the electrostatic energy. This is the case in the dicationic binuclear complex $\left[\mathrm{Fe}_{2} \mathrm{Cp}_{2}\left(\mu_{2}, \eta^{12}\right.\right.$-biphenyl) $]\left[\mathrm{PF}_{6}\right]_{2}$ that is reduced in a single two-electron wave 
to the neutral complex $\left[\mathrm{Fe}_{2} \mathrm{Cp}_{2}\left(\mu_{2}, \eta^{10}\right.\right.$-bicyclohexadinylidene)] (Schemes 2, 61].

A related example was shown by Geiger in the octahedral cluster $\left.\left[\mathrm{Os}_{6}(\mathrm{CO})_{18}\right)\right]^{2-}$ that is oxidized in a reversible two-electron wave to the monocapped trigonal neutral cluster at $30^{\circ} \mathrm{C}$ [62]. Electrochemical reversibility depends on the conditions (electrochemical time scale and temperature) [21, 22, 63]. In natural and unnatural energy-conversion processes, electron transfer often is accompanied by proton transfer. This is the case for many transition-metal-oxo redox catalysts (typically $\left.\mathrm{L}_{\mathrm{n}} \mathrm{Ru}=\mathrm{O}\right)[64,65]$ in which the oxo ligand weakly binds acidic hydrogen atoms of proton donors. In many of these cases proton transfer is coupled with electron transfer, and both events occur simultaneously. Excellent reviews on proton-coupled electron transfer reactions are provided [64-66], and this subject will not be further treated here although many essential redox catalysts are concerned.

\section{Electron transfers from Hexa-Iron redox centers: A new electrostatic paradigm}

Hexa(ferrocenylethynyl)benzene is an interesting example of a six-electron transfer system. Using [n$\left.\mathrm{Bu}_{4} \mathrm{~N}\right]\left[\mathrm{PF}_{6}\right] \quad 0.1 \mathrm{M}$ as an electrolyte in $\mathrm{CH}_{2} \mathrm{Cl}_{2}$, anodic oxidation on $\mathrm{Pt}$ shows a single wave with $\mathrm{Ep}_{\mathrm{a}}-\mathrm{Ep}_{\mathrm{c}}=60$ $\mathrm{mV}$ at $30^{\circ} \mathrm{C}$ as expected for a chemically and electrochemically reversible transfer of 6 electrons leading to hexa(ethynylferricenium), meaning that the redox centers are apparently too distant from one another to exert significant electronic and electrostatic factors [67, 68]. Using the Bard-Anson equation [69], the calculated number of transferred electrons is very close to 6 . Using $\left[n-\mathrm{Bu}_{4} \mathrm{~N}\right]\left[\mathrm{BAr}_{4}^{\mathrm{F}}\right] 0.1 \mathrm{M}$ as an electrolyte in $\mathrm{CH}_{2} \mathrm{Cl}_{2}$, however, three well separated two-electron waves are observed (Scheme 3). Note that this later electrolyte, contrary to the former one, contains a large counter anion forming with the cationic ferricenium unit a completely dissociated ion pair in which ion pairing is loose and the cationic charge exacerbated for electrostatic effects. This means that the electrostatic effects should be much more pronounced with this larger electrolyte [70, 71].

Let us consider such enhanced electrostatic effects among the six ferrocenyl centers. For this purpose, the three related bis(ethynylferrocenyl)benzene complexes in which the two substituents around the benzene ring are in ortho, meta and para position, respectively, have been synthesized and analyzed electrochemically. Given the free rotation of the ferrocenyl group around the exocyclic single bond, the two ferrocenyl groups orientate in opposite side from the benzene plane in all three complexes, minimizing the electrostatic effects. The complexes in which the two ferrocenylethynyl groups are in

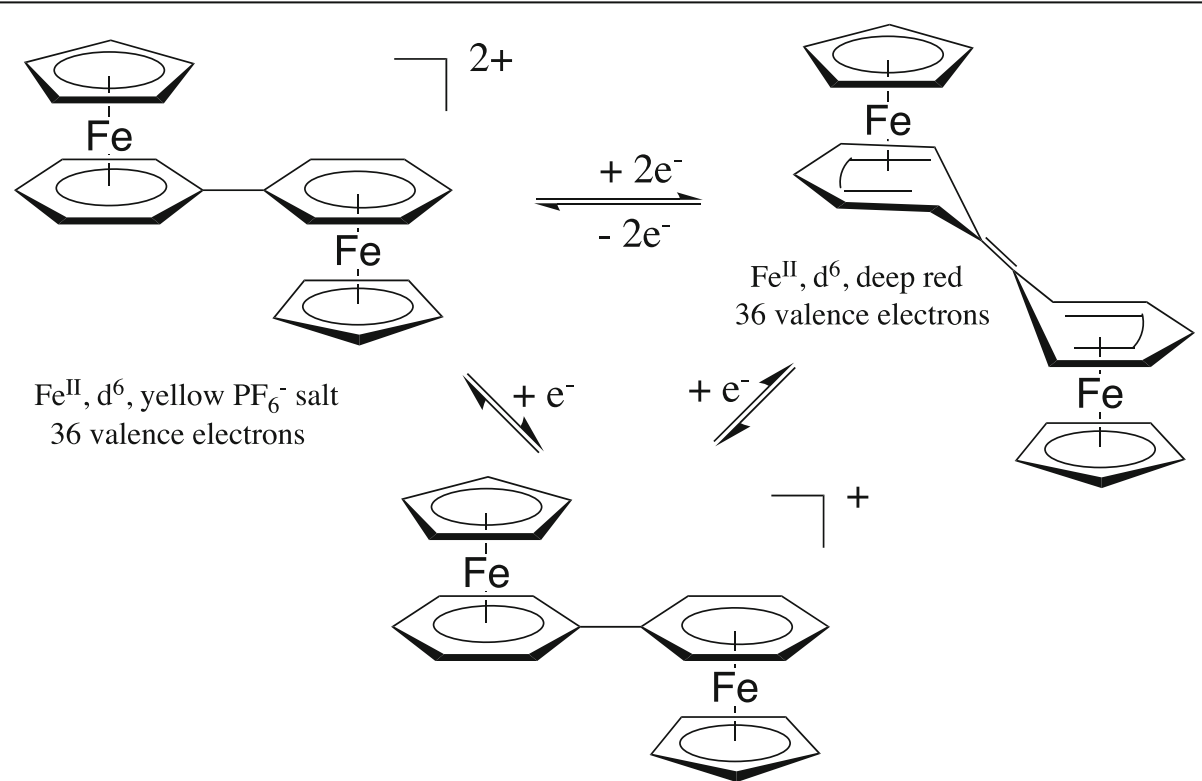

Average-valence $\mathrm{Fe}^{\mathrm{I}}-\mathrm{Fe}^{\mathrm{II}}, \mathrm{d}^{6}-\mathrm{d}^{7}, 37$ valence electrons

purple $\mathrm{PF}_{6}$ - salt, only visible and isolable for the $\mathrm{Cp}^{*}$ complex

Scheme 2 With $\left[\mathrm{Fe}_{2} \mathrm{Cp}_{2}\left(\mu_{2}, \eta^{12} \text {-biphenyl)][PF}\right]_{2}\right.$, only a single reversible 2-electron wave is observed by $\mathrm{CV}$, whereas with the $C \mathrm{P}^{*}$ analog $\left[\mathrm{Fe}_{2} \mathrm{Cp}_{2}{ }_{2}\left(\mu_{2}, \eta^{12}\right.\right.$-biphenyl) $]\left[\mathrm{PF}_{6}\right]_{2}$ two close single-electron waves are observed, and the average valence 37-electron complex is observable and isolable. In the first case the reorganization energy in the course of the 2 nd single electron transfer compensates the electrostatic energy differentiating reduction of a dication from that of a monocation, which does not completely occur in the 2 nd case. In both cases a biscyclohexadienylidene ligand resulting from intramolecular coupling within the diphenyl ligand is imposed by the 18-electron rule [61]. 

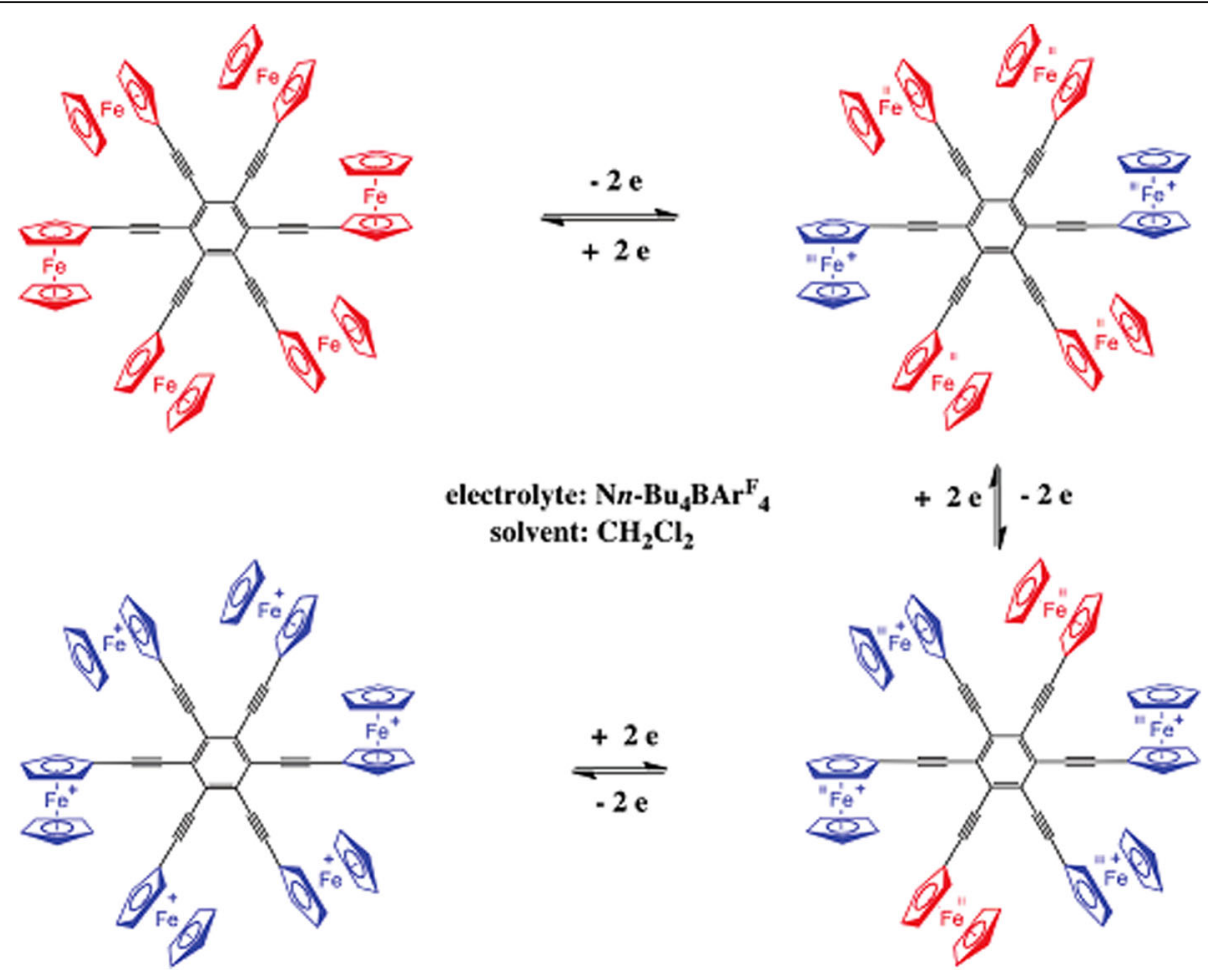

Scheme 3 Successive two-electron oxidation steps of hexa(ferrocenylethynyl)benzene with $\left[n-\mathrm{Bu}_{4} \mathrm{~N}\right]\left[\mathrm{BAr}_{4}{ }_{4}\right]$ in $\mathrm{CH}_{2} \mathrm{Cl}_{2}$ based on electrostatic effects related to the conformation of the ferrocenyl group around the benzene plane. Reprinted with permission from ref. [68]. Copyright 2011 American Chemical Society.

meta or para are oxidized in a single electron wave even with $\left[n-\mathrm{Bu}_{4} \mathrm{~N}\right]\left[\mathrm{BAr}_{4}^{\mathrm{F}}\right]$ as electrolyte, whereas the ortho derivative shows, with this electrolyte, two distinct single-electron waves. In this later case, even if the two ferrocenyl are in transoid conformation, they are close to each other and are the subject of a significant electrostatic effect.

Let us now consider the bis- and tris(ferrocenylethynyl)benzene complexes in which the groups are in meta position relative to one another. With $\left[n-\mathrm{Bu}_{4} \mathrm{~N}\right]\left[\mathrm{PF}_{6}\right] 0.1$ $\mathrm{M}$, these two compounds show a single two-electron wave, but with $\left[n-\mathrm{Bu}_{4} \mathrm{~N}\right]\left[\mathrm{BAr}_{4}^{\mathrm{F}}\right] 0.1 \mathrm{M}$ there is a remarkable difference between the electrochemical behaviors of these two complexes. The complex 1,3-bis- (ferrocenylethynyl)benzene shows a single 2-electron wave with $\mathrm{Ep}_{\mathrm{a}}-\mathrm{Ep}_{\mathrm{c}}=60 \mathrm{mV}$ at $30{ }^{\circ} \mathrm{C}$ whereas, under these conditions, 1, 3, 5-tris-(ferrocenylethynyl)benzene shows three well distinct single-electron waves. This striking contrast between the bis- and tris-meta substituted complexes is explained by the frustration phenomenon. Whereas the disubstituted complex can bear the two ferrocenyl groups in transoid position to avoid any electrostatic effect, this is no longer the case for the tris complex due to frustration, i.e. the third ferrocenyl group must choose between a cisoid and a transoid conformation and finally probably adopts an intermediate conformation between cisoid and transoid, so that electrostatic repulsion occurs between the three ferrocenyl redox centers [68]. Such a frustration phenomenon has already been encountered in magnetic properties [72]. These experiments clearly illustrate the situation for which electrostatic effects are observed in multi-centered organometallic compounds and the crucial role of supporting electrolytes in exacerbating these effects by variation of counter ion sizes. These experiments allow understanding the three two-electron waves observed for hexa(ferrocenylethynyl)benzene. It is remarkable that the cyclovoltammograms are the same for the 1,3,5-tris- and the hexa-substituted complexes: both compounds show a single wave with $\left[n-\mathrm{Bu}_{4} \mathrm{~N}\right]\left[\mathrm{PF}_{6}\right]$ and 3 equal-intensity waves with $\left[n-\mathrm{Bu}_{4} \mathrm{~N}\right]\left[\mathrm{BAr}_{4}^{\mathrm{F}}\right]$. We know that two ferrocenylethynyl groups in para position are not the subject of electrostatic effect with any electrolyte, which explain why they are oxidized within the same electrochemical wave, whereas both the meta and ortho ferrocenylethynyl groups are the subject of electrostatic effects. This analysis allows one to understand how the ferrocenyl groups are oxidized in hexa(ferrocenylethynyl)benzene with the latter electrolyte in $\mathrm{CH}_{2} \mathrm{Cl}_{2}$, i.e. two para ferrocenyl groups at a time (Scheme 3) [68].

Whereas, large cores with six ferrocene termini show simple six-electron anodic oxidation [73], other hexaferrocene complexes are of interest. The electrochemistry 
of cyclic hexaferrocenes has indeed been reported in which the ferrocene units are directly bonded to one another [74] (Fig. 1) or linked between one another by a $\mathrm{SiMe}_{2}$ preventing significant electronic communication between the redox centers (Fig. 2) [75]. In the former case, both electronic and electrostatic interactions allow a given ferrocene unit to sense the first, second and third neighbors so that four single-electron waves are observed; whereas, the two last $\mathrm{CV}$ waves involving high positive charge numbers are beyond the electrochemical window [74]. In the latter case, the electrostatic influence of the first neighbors is observed, but that of the next ones is not, so that only two 3-electron waves are observed. In this family of cyclic ferrocene bridged by a $\mathrm{SiMe}_{2}$ group, however, three waves of different intensities were observed with an odd number of dimethylsilylferrocenyl units [75].

\section{Multi-Electron transfers in redox-active polymers}

The richest family of redox-active metallopolymers is by far that of ferrocene-containing polymers in which the ferrocene groups are located along the polymer chain $[76,77]$ or on the side arms [78, 79]. For a long time, polymerization remained uncontrolled, but during the last decade methods of living polymerization [80] greatly improved the field of polymer materials. The most wellknown ferrocene polymer family is that developed by Manners by the ring-opening polymerization of dimethylsilyl-bridged ansa-metallocenes, particularly with ferrocene yielding poly(dimethylferrocenyl)silane [76]. Oxidation of these polymers leads to class-II mixed-valence redox systems with an inter-valent absorption band at $1100-1300 \mathrm{~nm}$. Their electrochemistry shows two equal-intensity CV waves observed at 0.00 and $0.24 \mathrm{~V}$ vs. ferricenium/ferrocene, respectively, as a result from the electrostatic interactions among the ferricenium centers [81].

The rational determination of the number of ferrocene units in polymers, i.e. the degree of polymerization was shown by Bard and Anson in 1978 with a poly(vinylferrocene) polymer according which the electrons are transferred one by one statistically from independent redox centers [69]. The result of the theoretical treatment is that the CV wave should show the same shape as that of the monomeric species in the same environment, but the diffusion current reflects the number of identical redox centers. Thus, the number of transferred electrons $n_{p}$ is provided by the ratio of diffusion current intensities of the polymer $i_{p}$ and monomer $i_{m}$ respectively, and also depends on the diffusion coefficient $D_{m}$ and $\mathrm{D}_{\mathrm{p}}$ of the monomer and polymer, respectively. The ratio of the latter is related to that of the molecular weights $M_{m}$ and $M_{p}$ of the monomer and polymer, respectively:

$$
\mathrm{D}_{\mathrm{p}} / \mathrm{D}_{\mathrm{m}}=\left(\mathrm{M}_{\mathrm{m}} / \mathrm{M}_{\mathrm{p}}\right)^{0.55}[82]
$$

Since oxidation of the vinylferrocene monomer is an one-electron oxidation to vinylferricenium, an equation providing $n_{p}$ was empirically provided from $d c$ polarography:

$$
\mathrm{n}_{\mathrm{p}}=\left(\mathrm{i}_{\mathrm{dp}} \mathrm{C}_{\mathrm{m}} / \mathrm{i}_{\mathrm{dm}} \mathrm{C}_{\mathrm{p}}\right)\left(\mathrm{M}_{\mathrm{p}} / \mathrm{M}_{\mathrm{m}}\right)^{0.275}[69,83]
$$

This equation can be used in the absence of precipitation, adsorption and slow electron transfer at the electrochemical time scale. Thus, the choice of solvent is important, because it must solubilize both the oxidized and reduced forms of the metallopolymer and insure their chemical stabilities at least during this electrochemical time scale. The equation is useful to determine the number of redox centers $n_{p}$ in relatively small- or modest-sized metallomacromolecules, and the risk of
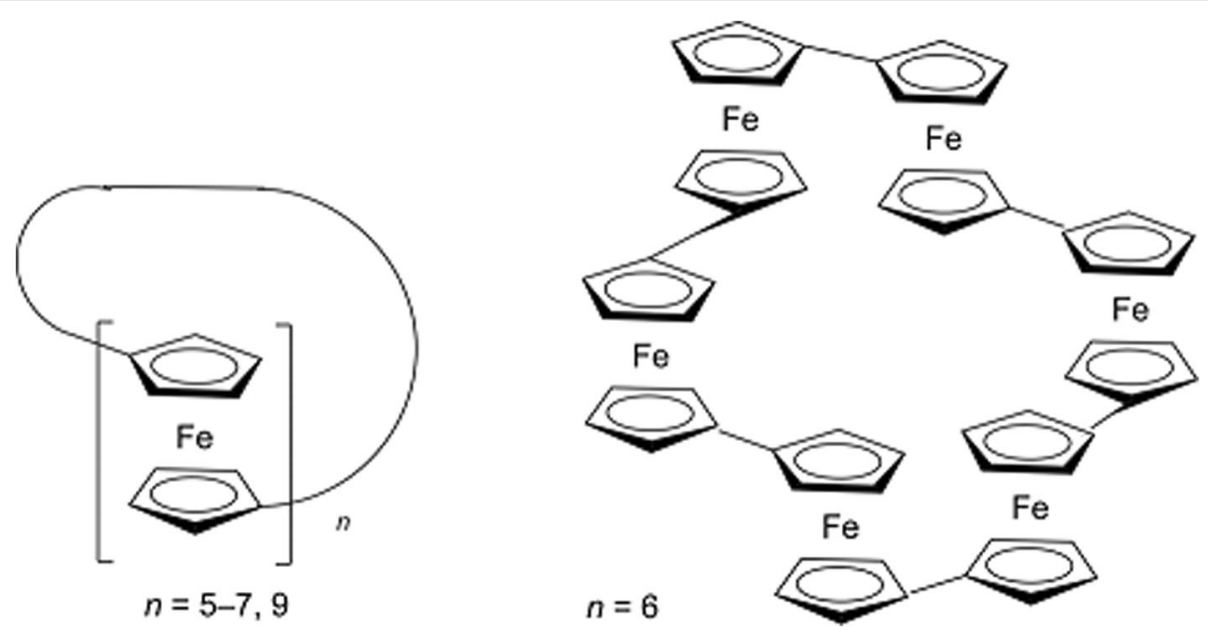

Fig. 1 Cyclic hexaferrocene (four single-electron transfer $\mathrm{CV}$ waves are observed, the two others being out of scale) and other cyclic poly(ferrocenes), F $c_{n}$ [74] 


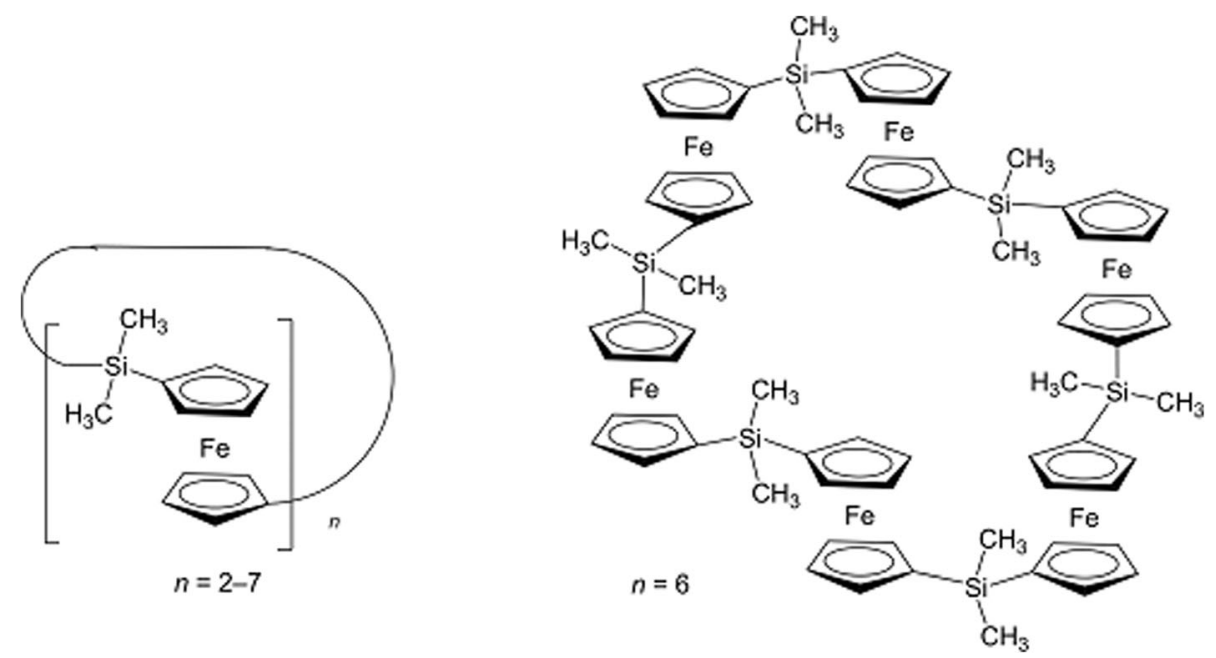

Fig. 2 Cyclic hexa(ferrocenyldimethylsilane). Electrostatics effect are only observed between a ferrocene group and its two neighbors, but not with further neighbors. As a consequence, two 3-electron waves are seen by cyclic voltammetry [75]

departure for incorrect results increases together with the molecular weight due in particular to adsorption. In late transition-metal sandwich complexes, the oxidized and reduced form interconversion undergoes only minute structural variation (minute change of the metalligand bond) that are fast on the electrochemical time scale, at least in the range of 17-19 electrons in the valence electron shell, because the full metal-sandwich structure is retained [13].

A particularly efficient living polymerization method is the ring-opening metathesis polymerization (ROMP) developed by the groups of Schrock and Grubbs with their transition metal alkylidene catalysts [84-88]. Recently efficient syntheses using Grubbs' 3rd-generation ROMP catalyst [89, 90] of such precise ferrocene-containing polymers and copolymers in which the ferrocene or cobalticenium groups are located on the polymer side arms have been developed [91-107]. Such metallopolymers have also been synthesized in which the electron-reservoir sandwich complex $\left[\mathrm{CpFe}^{\mathrm{II}}\left(\eta^{6}-\mathrm{C}_{6} \mathrm{Me}_{6}\right)\right]\left[\mathrm{PF}_{6}\right], \mathrm{I}$, has also been branched on the side chain [108]. Multiblock metallocopolymers have been synthesized containing a combination of blocks of ferrocene, pentamethyl ferrocene, cobalticinium, $\left[\mathrm{CpFe} \mathrm{e}^{\mathrm{II}}\left(\eta^{6}-\right.\right.$ $\left.\left.\mathrm{C}_{6} \mathrm{Me}_{6}\right)\right]\left[\mathrm{PF}_{6}\right]$, and solubilizing polyethylene glycol blocks. Polymers containing the four distinct sandwich blocks have also been fabricated as macromolecular electrochromes. All the different redox systems of the tetrablock metallocopolymer have different colors, and each of them that is redox switchable either by application of a given potential or a redox reagent of specific driving force possesses two redox forms of distinct colors [109]. In all these living metallopolymers, the determination of the numbers of redox units is all the easier as these metallopolymers are monodisperse given the living polymerization process. These numbers where determined by the Bard-Anson formula and confirmed by the end-group analysis by ${ }^{1} \mathrm{H}$ NMR, MALDI TOF mass spectrometry and UV-vis. Spectroscopy, in particular when the degree of polymerization (DoP) was not too high. In the case of high metallopolymers, the solubility must be designed, for instance upon involvement of a PEG block and introduction of a solubilizing block as the first block, such that the ${ }^{1} \mathrm{H}$ NMR yield be quantitative and the final polymer remains soluble. In these cases, and if these conditions are fulfilled the number of redox units is the DoP of the living metallopolymer, as confirmed by the Bard-Anson formula.

Ferrocene-containing polymers, as ferrocene itself, rapidly reduce $\mathrm{Au}(\mathrm{III})$ and $\mathrm{Ag}(\mathrm{I})$ to $\mathrm{Au}$ and $\mathrm{Ag}$ nanoparticles (NPs), respectively, although the driving force of these reactions is weak, producing AuNPs and AgNPs of relatively large sizes such as 15 to $25 \mathrm{~nm}[110,111]$. AuNPs and AgNPs are well-known for their catalytic redox $[59,112,113]$ and antimicrobial properties, respectively. AuNP catalysts are efficient if they are very small, thus this mode of $\mathrm{Au}(\mathrm{III})$ reduction is not adequate for that purpose, but can be replaced by reduction of $\mathrm{Au}(\mathrm{III})$ by $\mathrm{NaBH}_{4}$ in the presence of the polymer. $\mathrm{NaBH}_{4}$ is a strong reducing agent that produces ferrocene polymer-stabilized small AuNPs [59]. Thus, among the above-mentioned ferrocene polymers, several of them have been used in this way and applied to the AuNP-catalyzed nitrophenol reduction [105-107, 114].

\section{Electron transfers with Metallodendrimers and Metallodendronic polymers}

Forty years ago, the advent of the dendrimer field has boosted the area of macromolecules [115-119]. In this context metallodendrimers have been privileged given 
their application in molecular electronics, sensing, biomedical areas, and catalysis [120-126]. Redox-active metallodendrimers have included $\mathrm{Ru}(\mathrm{II})$-polypyridine dendrimers largely developed in particular by Balzani's group; these metallodendrimers can not only be oxidized to their $\mathrm{Ru}(\mathrm{III})$ counterparts but also harvest visible light and eventually direct photons like antennas [120]. The other metallodendrimer family of interest is that of ferrocene and other transition-metal-sandwich dendrimers due to the chemically and electrochemically reversibility of ferricenium/ferrocene couple and other related systems in these dendrimers. Reviews are available for the syntheses, structures and electrochemical studies of this very abundant family of macromolecules with ferrocene groups located at the core, branches or peripheries of dendrimers [121, 127, 128]. Two areas involving this redox $\mathrm{Fe}{ }^{\mathrm{III}} / \mathrm{Fe}^{\mathrm{II}}$ system are of interest here, that of redox recognition/redox sensing and that of molecular electronics and its applications in the materials and biomedical field. The first ferrocene dendrimers as well as their redox sensing properties towards oxo-anions were reported in 1996. This included the very remarkable positive dendritic effect, i.e. the magnitude of the sensing effect of the $\mathrm{HSO}_{4}{ }^{-}$and $\mathrm{H}_{2} \mathrm{PO}_{4}{ }^{-}$anions by amidoferrocenyl groups of amidoferrocenyl-terminated dendrimers was all the more important as the dendrimer generation was higher $[129,130]$. Three interactions were involved in this positive dendritic sensing effect: (i) the electrostatic attraction between the ferricenium group and the sensed anion (in the monomer; this interaction provokes only little recognition); (ii) the supramolecular interactions (double hydrogen bonding) between the amido group and the anion, and (iii) the dendritic effect encapsulating the anion that is key effect in synergy with the two other effects (Fig. 3).

The sensing effects were pursued using these powerful principles with various iron-sandwich-terminated dendrimers for halide anions [131] and ATP anion with gold nanoparticle-cored stars [132] and covalent [133] or even hydrogen-bonded (supramolecular) dendrimers (Fig. 4) [134].

Dendrimer syntheses in our research group were based on the general original one-pot $\mathrm{CpFe}^{+}$-induced polyfunctionalization of polymethylarenes by a series of multiple benzylic deprotonation/allylation sequences applied to arenes bearing various number of methyl groups around benzene [135-138]. In these syntheses, the $\mathrm{CpFe}^{+}-$induced nona-allylation of mesitylene was particularly useful, because it directly introduced $1 \rightarrow 3$ branching that was further continued upon dendrimer construction based on related tribranched dendrons [136, 137]. Whereas $1 \rightarrow 2$ branching is dominant in dendrimer chemistry [115, 117-125], $1 \rightarrow 3$ branching, pioneered by Newkome with his [27]-arborol [139, 140], is powerful both in terms of much more rapid dendrimer construction as for its encapsulation properties that are essential in sensing and catalysis with dendrimer templates. Triferrocenyl dendrons were designed in order to form, by $1 \rightarrow 3$ connectivity, ferrocenyl-terminated dendrimers upon Williamson or $\mathrm{Cu}(\mathrm{I})$-catalyzed click chemistry [141-143]. Alternatively, azido-terminated dendrimers were "clicked" with alkynyl ferrocene or alkynylcobalticenium to synthesize triazolylmetallocene-terminated dendrimers that proved to be excellent oxo-anion and metal cation electrochemical sensors due to selective supramolecular interactions (Scheme 4) [144-146].

- Double hydrogen bonding:

$$
\mathrm{x}=0 \text { or }+1
$$

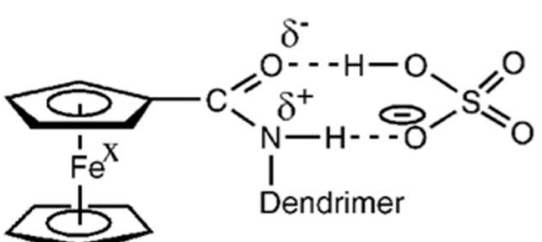

- Electrostatic attraction specific to the cationic form

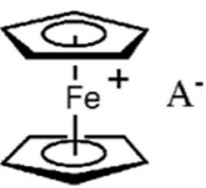

- Topology. Dendritic effect: Steric compression and channel/ cavity effect at the dendrimer periphery

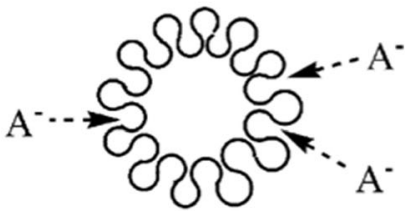

Fig. 3 The three factors acting in synergy explaining the recognition and sensing by amidoferrocene-terminated dendrimers of oxo-anions $\left(\mathrm{HSO}_{4}{ }^{-}, \mathrm{H}_{2} \mathrm{PO}_{4}{ }^{-}\right.$and $\left.\mathrm{ATP}^{2-}\right)$ and the remarkable positive dendritic effect in anion redox sensing [130] 


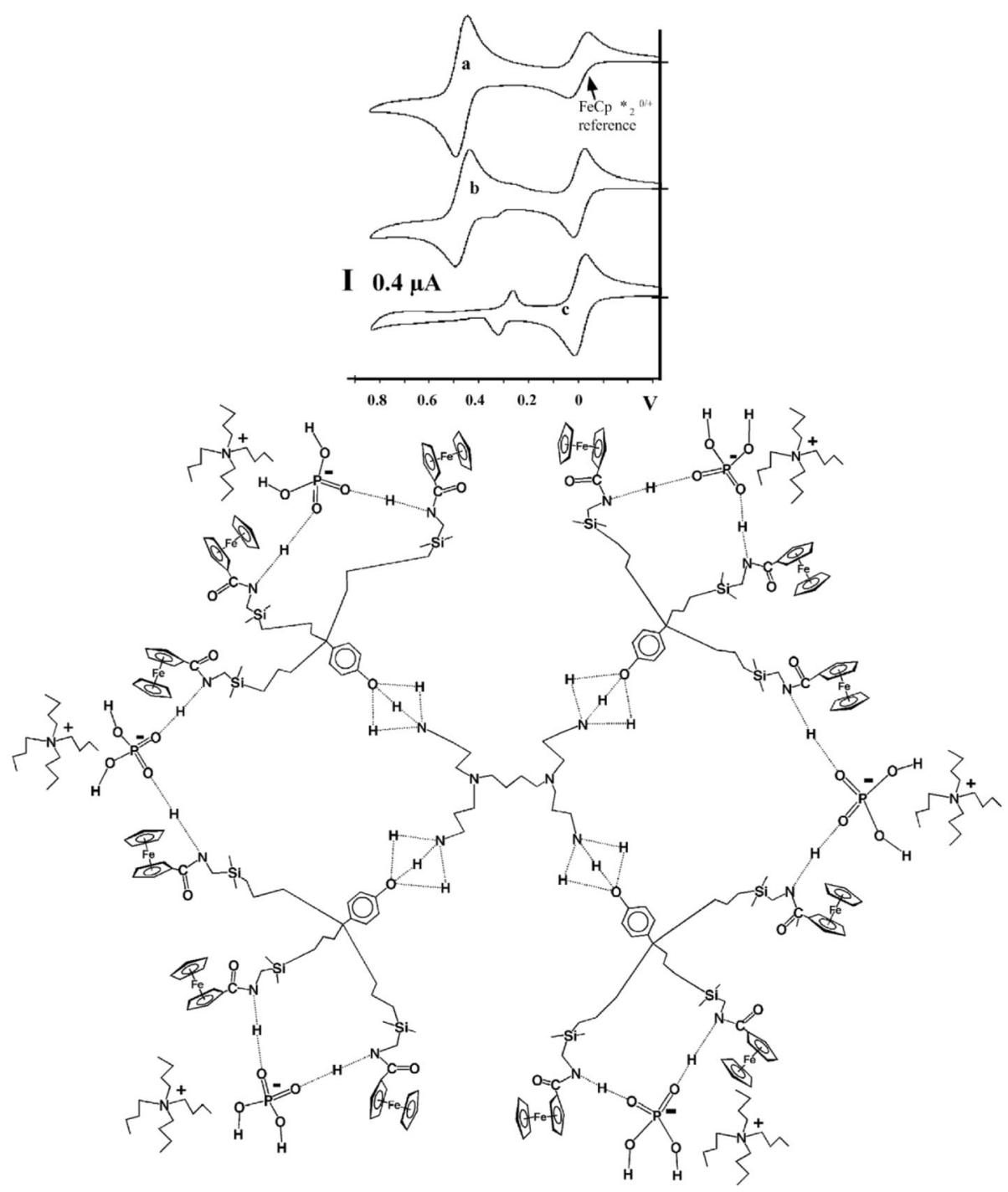

Fig. 4 Sensing of $\mathrm{H}_{2} \mathrm{PO}_{4}^{-}$by the supramolecular metallodendrimer: Titration using cyclic voltammetry in $\mathrm{CH}_{2} \mathrm{Cl}_{2}\left(\mathrm{Pt}, 0.1 \mathrm{M}\left[n \mathrm{Bu}_{4} \mathrm{~N}\right]\left[\mathrm{PF}_{6}\right]\right.$, reference $\mathrm{FeCp}_{2}{ }_{2}\left(\mathrm{Cp}^{*}=n^{5}-\mathrm{C}_{5} \mathrm{Me}_{5}\right)$ of the supramolecular amidoferrocene dendrimer by $\left[n \mathrm{Bu}_{4} \mathrm{~N}\right]\left[\mathrm{H}_{2} \mathrm{PO}_{4}\right]$ : (a) before addition of $\left[n \mathrm{nu}_{4} \mathrm{~N}\right]\left[\mathrm{H}_{2} \mathrm{PO}_{4}\right] ;$; (b) after addition of 0.4 equiv.; (c) 0.5 equiv. The dramatic intensity drop at the equivalent point shows the sharp decrease of the diffusion coefficient reflecting the sudden formation of the large supramolecular assembly proposed here in which each $\mathrm{H}_{2} \mathrm{PO}_{4}{ }^{-}$group binds two amidoferrocene groups corresponding to the observed stoichiometry [134]. Copyright 2003 American Chemical Society

Electron tunneling from the ferrocene centers through various dendrimers has been demonstrated $[147,148]$ as well as electronic wiring through isolating nanochannels involving molecular sieving with vertically aligned mesoporous silica films [149].

Despite the relative stability of ferricenium, long-term decomposition of its derivatives for instance in the presence of air and in solution still poses problems (especially with electron-withdrawing linkers), and indeed the oxidation of ferrocene dendrimers has rarely been addressed otherwise than in electrochemistry studies. An excellent solution to stabilize ferricenium, however, is the use of the $\eta^{5}-\mathrm{C}_{5} \mathrm{Me}_{5}$ ligand $\left(\mathrm{Cp}^{*}\right)$ instead of the parent $\eta^{5}-\mathrm{C}_{5} \mathrm{H}_{5}$ ligand (Cp). Cp* is an extremely efficient stereoelectronic protector in overall organometallic chemistry. Several generations of pentamethylamidoferricenium dendrimers with $1 \rightarrow 3$ connectivity have been isolated upon oxidation of their neutral counterparts using ferricinium hexafluorophosphate and characterized and are stable in air even in solution [143]. Giant ferrocenyl- and pentamethylferrocenyl with $1 \rightarrow 3$ connectivity up to about 15,000 redox termini have been synthesized under both their $\mathrm{Fe}(\mathrm{II})$ and $\mathrm{Fe}(\mathrm{III})$ forms (ferricenium dendrimers are obtained by acetylferricenium oxidation of ferrocene dendrimers). Their electrochemistry shows full chemical and electrochemical stabilities, which 

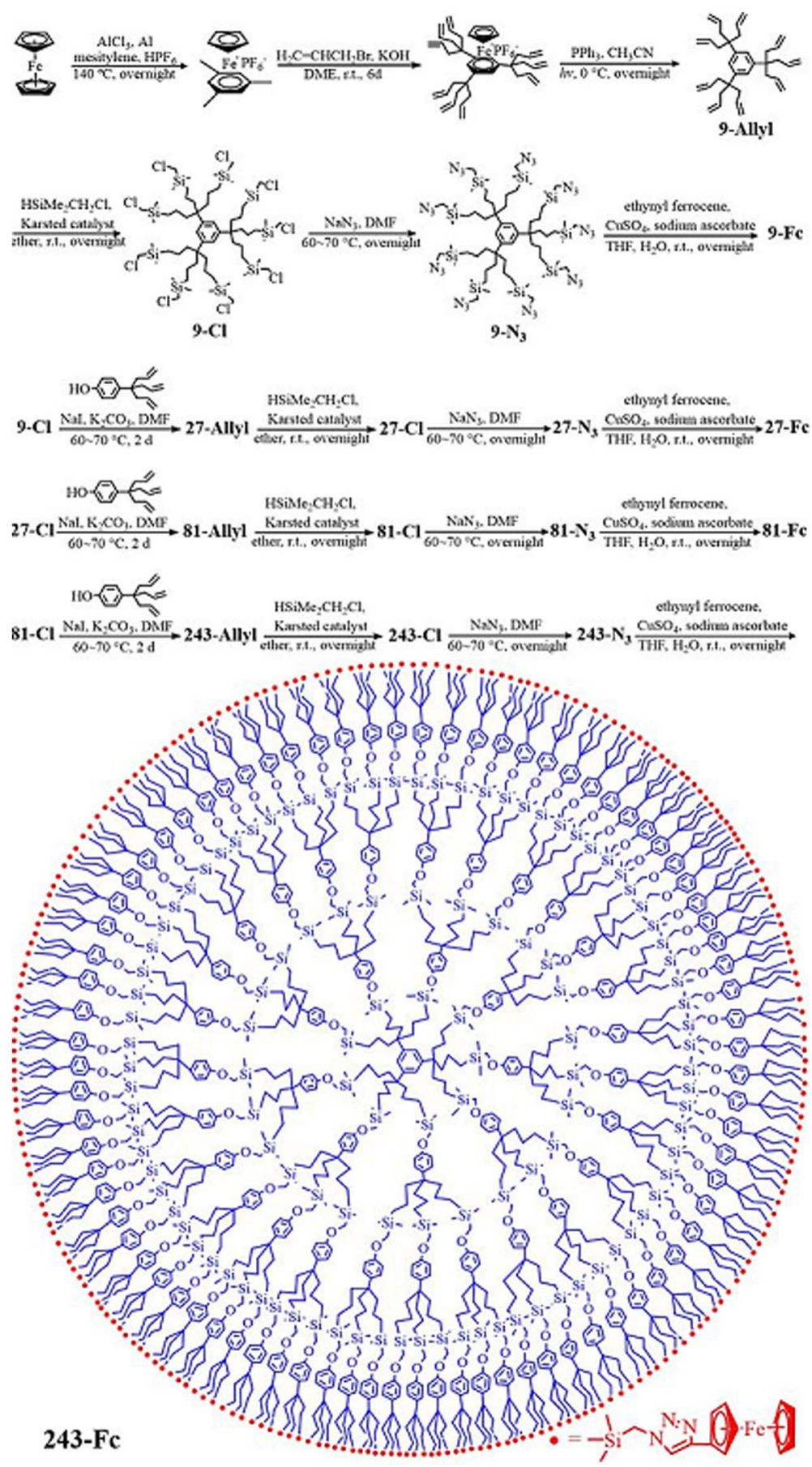

Scheme 4 Syntheses starting from ferrocene and mesitylene of 4 generations (9-Fc, 27-Fc, 81-Fc and 243-Fc) of triazolylferrocene-terminated dendrimers. These metallodendrimers cleanly react with aq. $\mathrm{HAuCl}_{4}$ producing large, robust water-soluble gold nanoparticles (AuNPs) stabilized by the ferricenium chloride dendrimers [144].

means that electron transfer among the redox centers and to the electrode proceeds by ultra-fast electron hoping among the redox sites and/or dendrimer rotation occurring faster than the electrochemical time scale. AFM shows that the dendrimer size reversibly increases by about $50 \%$ upon oxidation, probably due to repulsion among the multiple cationic ferricenium termini- a type of molecular "breathing" or molecular machine [150]. The full stability of such pentamethylferricenium dendrimers shows that these systems could be used in particular for applications to molecular batteries [151-153] and nanomedical devices [154-156] (Fig. 5). 
orange, neutral

ferrocenyl dendrimer

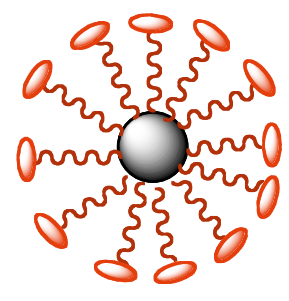

$\mathrm{G}_{5}(2000 \pm 100$

ferrocenyl termini)

$4.5 \pm 0.4 \mathrm{~nm}(\mathrm{AFM})$ dark-blue, positively-charged

ferricinium dendrimer
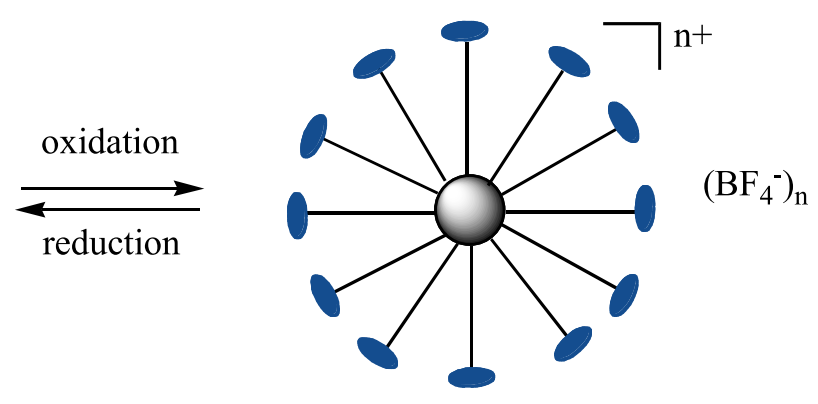

$\mathrm{G}_{5}(2000 \pm 100$

ferricinium termini)

$6.5 \pm 0.6 \mathrm{~nm}(\mathrm{EFM})$

Fig. 5 Reversible "breathing" (about 50\% size increase) of giant ferrocene-terminated dendrimers acting as a molecular machine upon oxidation to polycationic Fe(III) dendrimers due to mutual repulsion of positively charged redox centers in the Fe(III) form

Another way to oxidize ferrocene dendrimers or other ferrocene-containing macromolecules is to conduct oxidation with $\mathrm{Au}(\mathrm{III})$ or $\mathrm{Ag}(\mathrm{I})$ [96, 98, 110, 111, 157-159]. In this case $\mathrm{Au}(\mathrm{III})$, for instance, is reduced to $\mathrm{Au}(0)$ nanoparticles of relatively large size that are well encapsulated and protected by the ferricenium dendrimers formed in the redox reaction as reported in 2014 [157, 159]. In a recent study, triazolylferrocene dendrimers up to 243 peripheral redox centers for which this number was demonstrated to be $255 \pm 25$ using the Bard-Anson theory were shown to reduce aqueous $\mathrm{HAu}(\mathrm{III}) \mathrm{Cl}_{4}$ to purple water-soluble ferricinium chloride-stabilized AuNPs of 30 to $47 \mathrm{~nm}$ size. The later was reduced by cobaltocene to ferrocene dendrimer-weakly stabilized AuNPs from which the smaller dendrimers were extracted together with AuNP agglomeration; whereas, the 243-ferrocene dendrimer resisted extraction. This experiment demonstrated the specific ability of ferricenium dendrimer to strongly stabilize AuNPs and AgNPs for catalysis and antimicrobial activities respectively, although click ferrocene dendrimers still provided some stabilization through triazole coordination to the AuNP surface. Most if not all late transition-metal nanoparticles have been stabilized by click dendrimers and used for such functions (Scheme 5).

Ferrocene dendrimers, as well as other dendrimers [160], also stabilize small Au NPs if $\mathrm{NaBH}_{4}$ is used in the presence of the dendrimer to reduce $\mathrm{HAuCl}_{4}$ to small AuNPs, the driving force of $\mathrm{NaBH}_{4}$ being considerably superior to that of ferrocene derivatives for $\mathrm{Au}(\mathrm{III})$ and $\mathrm{Ag}(\mathrm{I})$ reduction, which explains the large difference of AuNP and AgNP size obtained. Likewise, analogous processes are achieved using click ferrocenecontaining polymers and dendronized ferrocene polymers [105, 161-167]. The advantage of the stabilization of small AuNPs is that they are much more efficient as catalysts [114, 168-170] for nitrophenol reduction by $\mathrm{NaBH}_{4}$ to aminophenol than large AuNPs formed using only a ferrocene reductant [110, 111]. In these "clicked" dendrimers, the $A u(I I I)$ and other cation stabilization by the triazole ligand is the key to further intradendritic small AuNP (and other metal NP) stabilization, because the triazole ligand stabilize both the metal cation and (more weakly) the NP [171-175]. A typical example is provided by Wang's work whereby similar-sized click and nonclick dendrimers where compared for $\mathrm{Au}(\mathrm{III})$ reduction with AuNP formation: with the click dendrimer small AuNPs were encapsulated within the dendrimer interior, whereas with the non-click dendrimers large AuNPs were stabilized outside the dendrimer by several dendrimers (Fig. 6) [159].

\section{Concluding remarks}

In conclusion, most electron-transfer processes in metallodendrimers can be compared to some extent to those occurring in metalloproteins [176-179] and neuronal networks [180]. The most current redox centers used in dendrimers for this purpose have been included in this mini-review. Besides the most commonly encountered ferrocene and related iron-sandwich systems, some other redox-active groups such as cobaltocene, metalloporphyrins, iron-sulfur clusters, ruthenium polypyridines and methylviologen have also sometimes been used in metallomacromolecules [14]. Iron sandwich complexes have been most used and are most useful because of the robustness of the redox systems whose structural design has been optimized for this purpose and due to the ease 


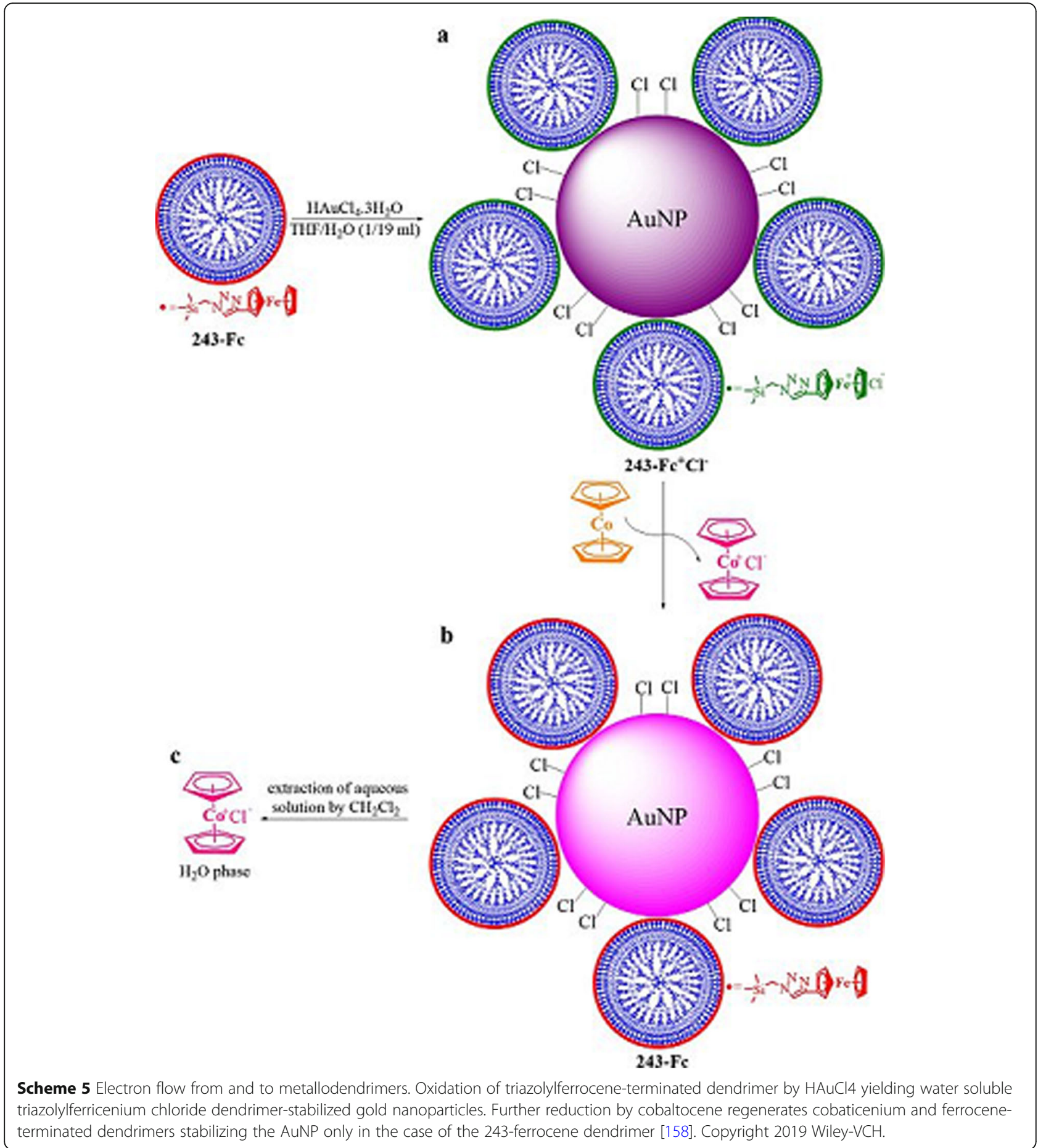

of their functionalization for linking to macromolecules. Electron-transfer properties found for the monomers can be advantageously extended to macromolecules. This is striking for the sensing properties for which the confinement indispensable inside the network allows boosting redox recognition with a remarkable positive dendritic effect. Electrostatic effects are shown to depend on the design and increase enormously when they are dealing with peripheral chargeable cationic redox centers, i.e. in the presence of large counter anions. Starting with organoiron electron-reservoir complexes applications range from electrochemical references and stoichiometric redox reactions to electrocatalysis (electron-transfer-chain catalysis) and redox 


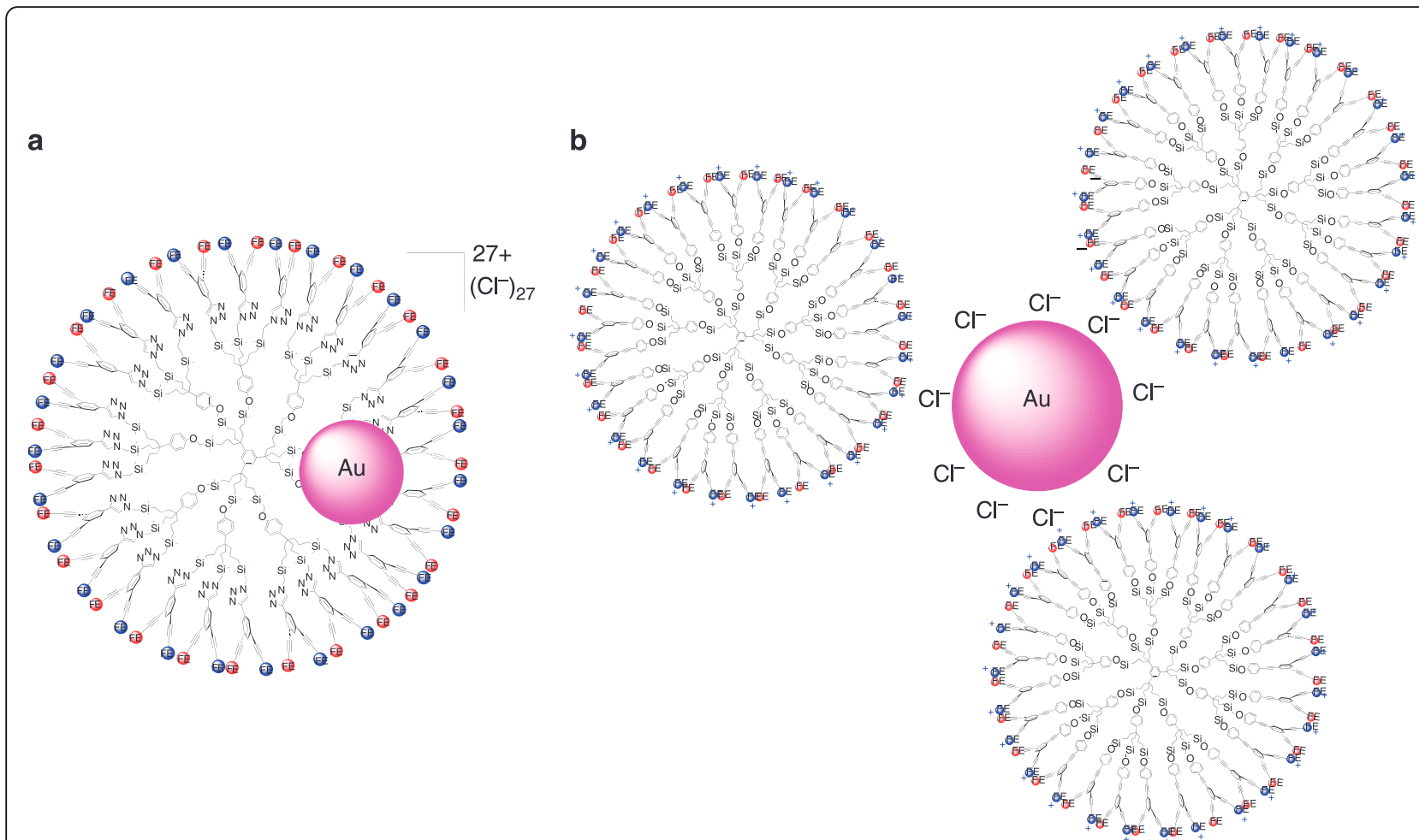

Fig. 6 AuNP syntheses from metallodendrimers. Metallodendrimers containing $54 \mathrm{Cp}$ Fe(II) dppe redox termini were synthesized by two methods: click coupling between azido-terminated dendrimers forming triazole linkers, (a) and Sonogashira coupling that did not provide such intradendritic ligands (b). Two reactions of $\mathrm{HAuCl}_{4}$ were conducted with each of the two dendrimers: 1) reaction with the neutral dendrimers oxidizing them to class-2 mixed-valent polycationic dendrimers; 2) reaction with $\mathrm{NaBH}_{4}$ in the presence of these class-2 mixed-valent polycationic dendrimers. These two reactions produced AuNPs of closely related sizes, but the click dendrimers yielded small AuNPs inside the dendrimer (1.9 resp. $1.4 \mathrm{~nm}$ ), whereas the non-click dendrimers yielded large AuNPs (3.7 resp. $3.4 \mathrm{~nm}$ ). This series of experiments clearly shows the Au(III)-triazole coordination and intra-dendritic triazole stabilization of small AuNPs, whereas these phenomena are not occurring with non-click dendrimers that stabilize large AuNPs only outside dendrimers. Reprinted with permission of ref. [159]. Copyright 2015 Nature publishing group

mediation (outer-sphere) or redox catalysis (inner sphere). Single 2-electron transfer catalysts are desired for instance in $\mathrm{H}_{2}$ evolution processes. On the molecular level, they are accessible with chemically reversible systems in which the electrostatic energy required for the second electron transfer is compensated by the reorganization energy occurring in this step. In hexanuclear systems the electrontransfer mechanisms are intimately governed by the structure and electrostatic effect. In large and giant metallodendrimers in which the redox groups are located at the branch termini, the electronic and electrostatics effect can become so weak that they are insignificant, and transfer of up to 15,000 electrons in a single reversible CV was indeed observed in the absence of adsorption. Applications are not only the mimicry of electron-transfer proteins, but also more practical ones such as redox sensors, actuators, electrochromes, redox catalysts, catalyst templates, switchable drug delivery systems and batteries. In the metallodendritic assemblies around redox centers, supramolecular interactions such as multiple hydrogen bonding, electrostatic effects, weak coordination, $\pi-\pi$ stacking are playing a key role $[15,181-190]$.

\section{Acknowledgements}

Excellent contributions by colleagues and students to our research cited in the references, and funding by the institutions cited below are gratefully acknowledged as are multiple invitations, outstanding collaborations and warm hospitality in Chengdu by Drs Haibin Gu (Sichuan University, Chengdu) and Pengxiang Zhao (Chinese Academy of Engineering Physics, Jiangyou).

\section{Author's contributions}

The author(s) read and approved the final manuscript.

\section{Author's information}

Didier Astruc (didier.astruc@u-bordeaux.fr) is Professor of Chemistry at the University of Bordeaux, France, Member of the French Academy of Sciences, Institut Universitaire de France, Leopoldina Academy (National German Academy of Sciences), European Academy of Sciences, and Fellow of the Royal Society of Chemistry and Chemistry Europe.

\section{Funding}

The University of Bordeaux, the Centre National de la Recherche Scientifique (CNRS), the Institut Universitaire de France (IUF), the FP7 European Program "Nanosolution" and L'Oréal Research Center.

\section{Availability of data and materials}

The datasets analyzed during the current review are available in the references that have been specified in the article.

\section{Competing interests}

The author declares that he has no competing interests. 
Received: 16 April 2020 Accepted: 19 May 2020 Published online: 10 June 2020

\section{References}

1. Gatto G, Berg JM, Stryer L, Tymoczko J. Biochemistry. 9th ed. London: Palgrave Macmillan; 2019. ISBN 978-1319114657.

2. Gray HB, Wrinkler JR. Long-range electron transfer. Proc Nat Acad Sci. 2005; 102:3534-9.

3. Ciurli S, Musiani F. High potential iron-sulfur proteins and their role as soluble electron carriers in bacterial photosynthesis: tale of a discovery. Photosynth Res. 2005:85:115-31.

4. Dean DR, Seefeldt LC. Mechanism of nitrogen fixation by nitrogenase: the next stage. Chem Rev. 2014;114:4041-62.

5. Holm R, Kennepohl P, Solomon El. Structural and functional aspects of metal sites in biology. Chem Rev. 1996;96:2239-314.

6. Zhu J, Hu L, Zhao P, Lee LYS, Wong K-Y. Recent advances in Electrocatalytic hydrogen evolution using nanoparticles. Chem Rev. 2020;120:851-918.

7. Li Z, Ji S, Liu Y, Cao X, Tian S, Chen Y, Niu Z, Li Y. Well-defined materials for heterogeneous catalysis: from nanoparticles to isolated single-atom sites. Chem Rev. 2020;120:623-82.

8. Riley RS, June CH, Langer R, Mitchel MJ. Delivery technologies for cancer immunotherapy. Nat Rev Drug Discov. 2019;18:175-96.

9. Chen W, Li G. Tanning chemistry. 4th ed. Beijing: China Light Industry Press; 2018.

10. Handbook of porphyrin science with applications to chemistry, physics, materials science, engineering, biology and medicine. Kadish KM, Smith KM, Guilard R, eds. 2012. Singapore: World Scientific. ISBN-13: 978-9813140769.

11. Claessens CG, Hahn U, Torres T. Phthalocyanines: from outstanding electronic properties to emerging applications. Chem Record. 2008;8:75-97.

12. Juris A, Balzani V, Barigelletti F, Campagne S, Belser P, von Zelevsky A. Ru(II) Polypyridine complexes - Photophysics, photochemistry, electrochemistry, and Chemi-luminescence. Coord Chem Rev. 1988;84:85-277.

13. Astruc D. Organometallic chemistry and catalysis. Berlin: Springer; 2007. Chapter 11. ISBN: 978-3-540-46128-9.

14. Astruc D. Electron-transfer processes in dendrimers and their implication in biology, catalysis, sensing and nanotechnology. Nat Chem. 2012;4:255-67.

15. Lehn J-M. Supramolecular chemistry - scope and perspectives molecules, Supermolecules, and molecular devices (Nobel lecture). Angew Chem, Int Ed Engl. 1988;27:89-112.

16. Werner $\mathrm{H}$. At least 60 years of ferrocene: the discovery and rediscovery of the sandwich complexes. Angew Chem Int Ed. 2012;51:6052-8.

17. Astruc D. Why is Ferrocene so exceptional. Eur J Inorg Chem. 2017:6-29.

18. Vlcek AA. Formation and reduction of zero-Valent metal complexes studied Polarographically. Nature. 1956;177:1043-5.

19. Feldberg SW, Jeftic L. Nuances of the ECE mechanism. IV. Theory of cyclic voltammetry and chronoamperometry and the electrochemical reduction of hexacyanochromate(III). J Phys Chem. 1972;76:2439.

20. Taube H. Rates and mechanisms of substitution in inorganic complexes in solution. Chem Rev. 1952:52:69-126.

21. Astruc D. Electron Transfer and Radical Processes in Transition Metal Chemistry (Prefaced by Henry Taube). VCH, New York, 1995.ISBN 1-56081642-2.

22. Geiger WE in Progress in Inorganic Chemistry. Lippard SJ ed, Wiley, New York, 1985;33:p 275.

23. Connelly NG, Geiger WE. Chemical redox agents for organometallic chemistry. Chem Rev. 1996:96:877-910.

24. Sohn YS, Hendrickson DN, Gray HB. Electronic structure of ferricenium ion. J Am Chem Soc. 1970:92:3233-4.

25. Hurvois JP, Moinet C. Reactivity of ferricenium cations with molecular oxygen in polar organic solvents: decomposition, redox reactions and stabilization. J Organomet Chem. 2005;690:1829-39.

26. Mugner Y, Moïse C, Tirouflet J, Laviron E. Réduction électrochimique du ferrocène. J Organomet Chem. 1980;186:C49.

27. Astruc D, Hamon J-R, Althoff G, Román E, Batail P, Michaud P, Mariot J-P, Varret F, Cozak D. Design, stabilization and efficiency of organometallic "Electron reservoirs". 19-Electron Sandwichs $\eta^{5}-C_{5} R_{5} F e(I) \eta^{6}-C_{6} R_{6}$, a key class active in redox catalysis. J Am Chem Soc. 1979:101:5445-7.

28. Moinet C, Roman E, Astruc D. Electrochemical reduction of Cations $\eta^{5}$ Cyclopentadienyl Fe $\eta^{6}$-Arene in basic media. Study of the behavior of the radicals formed "in situ". J Electroanal Interfac Chem. 1981;121:241-6.
29. Astruc D. Organoiron Electron Reservoir Complexes. Acc Chem Res. 1986;19: 377-83.

30. Bossard C, Rigaut S, Astruc D, Delville M-H, Félix G, Février-Bouvier A, Amiell $J$, Flandrois $S$, Delhaès $P$. One-, two- and three-Electron reduction of $C_{60}$ using the Electron-reservoir complex $\left[\mathrm{Fe}^{\prime} \mathrm{Cp}\left(\mathrm{C}_{6} \mathrm{Me}_{6}\right)\right]$. J Chem Soc Chem Commun. 1993:333-4.

31. Méry D, Ruiz J, Astruc D. Use of an Electron-reservoir complex together with air to generate N-heterocyclic Carbenes. J Am Chem Soc. 2006;128:5602-3.

32. Fu F, Dedieu A, Wang W, Chen T, Song Y, Fouquet E, Hamon J-R, Zhu M, Astruc D. Stabilization of a new Nanocomposite family by reduction of gold Nanoclusters with Electron-reservoir complexes. Chem Commun. 2019;55: 10277-80.

33. Hamon J-R, Astruc D, Michaud P. Syntheses, characterizations, and stereoelectronic stabilization of organometallic electron reservoirs: the 19electron $d^{7}$ redox catalysts $\eta^{5}-C_{5} R_{5} F e(I) n^{6}-C_{6} R_{6}^{\prime}$. J Am Chem Soc. 1981;103: 758-66

34. Rajasekharan MV, Giesinski S, Ammeter JH, Oswald N, Hamon J-R, Michaud $P$, Astruc D. EPR studies of the electronic structure and dynamic Jahn-teller effect in iron(I) sandwich compounds. J Am Chem Soc. 1982;104:2400-7.

35. Green JC, Kelly MR, Payne MP, Seddon EA, Astruc D, Hamon J-R, Michaud P. Photoelectron study of Electron-reservoir Iron(I) Cyclopentadienyl Arene complexes. Organometallics. 1983;2:211-8.

36. Ruiz J, Lacoste M, Astruc D. Arene exchange by $P$ donors in the 19-Electron complexes Fe'Cp(Arene): kinetics, mechanism and salt effects; characterization and reactivity of the new 17-Electron and 19-Electron radicals Fe'Cp(PR3) $(n=2$ and 3). J Am Chem Soc. 1990;112:5471-83.

37. Brown DS, Delville MH, Boese R, Vollhardt KPC, Astruc D. Electron-reservoir complexes Fe'Cp(arene) as selective initiators for a novel Electron-transferchain catalyzed reaction: general synthesis of Fulvalene-bridged Homo- and Heterobimetallic zwitterions. Angew Chem, Int Ed Engl. 1994:33:661-3.

38. Rigaut $\mathrm{S}$, Delville $\mathrm{M}-\mathrm{H}$, Astruc D. Triple $\mathrm{C}-\mathrm{H} / \mathrm{N}-\mathrm{H}$ activation by $\mathrm{O}_{2}$ for molecular engineering: Heterobifunctionalization of the 19-Electron redox catalysts Fe'Cp(arene). J Am Chem Soc. 1997;119:11132-3.

39. Hamon JR, Astruc D, Roman E, Batail P, Mayerle JJ. $\eta^{5}$-benzyl-crystal structure, nucleophilic properties and electron-transfer reactions of $\mathrm{CpFe}\left(\eta^{5}\right.$ $\mathrm{C}_{6} \mathrm{Me}_{5} \mathrm{CH}_{2}$ ), an intermediate in $\mathrm{C}-\mathrm{H}$ ativation by $\mathrm{O}_{2}$ via $\mathrm{O}_{2}{ }^{-}$. J Am Chem Soc 1981;103:2431-2433

40. Rigaut S, Delville MH, Losada J, Astruc D. Water-soluble mono- and starshaped Hexanuclear functional organometallic catalysts for nitrate and nitrite reduction in water : syntheses and Electroanalytical study. Inorg Chim Acta. 2002;334:225-42

41. Ruiz J, Ogliaro F, Saillard J-Y, Halet J-F, Varret F, Astruc D. First 17-18-19Electron triads of stable Isostructural organometallic complexes. The $17-$ Electron complexes $\left[\mathrm{Fe}\left(\mathrm{C}_{5} \mathrm{R}_{5}\right)(\text { arene })\right]^{2+}(\mathrm{R}=\mathrm{H}$ or me), a novel family of strong oxidants: isolation, characterization, electronic structure and redox properties. J Am Chem Soc. 1998;120:11693-705

42. Gloaguen B, Astruc D. Chiral Pentaisopropyl- and Pentaisopentyl complexes: one-pot synthesis by formation of ten carbon-carbon bonds from Pentamethylcobaticinium. J Am Chem Soc. 1990;112:4607-9.

43. Madonik A, Astruc D. Electron-transfer chemistry of the 20-Electron complex $\left(\eta^{6}-\mathrm{C}_{6} \mathrm{Me}_{6}\right)_{2} \mathrm{Fe}^{0}$ and its strategic role in carbon-hydrogen bond. J Am Chem Soc. 1984;106:2437-9.

44. Kochi JK. Organometallic mechanisms and catalysis. New-York: Academic Press; 1978.

45. Ashby EC, Goel AB, de Priest RN, Prasad NS. Metal hydride reductions via single electron transfer. Evidence for an electron transfer pathway in the reactions of simple and complex metal hydrides of the main group metals with polynuclear hydrocarbons. J. Am Chem Soc. 1981;103:973-5.

46. Michaud P, Astruc D, Ammeter JH. Electron-transfer pathways in the reduction of $d^{6}$ and $d^{7}$ Organo-Iron Cations by $\mathrm{LiAlH}_{4}$ and $\mathrm{NaBH}_{4}$. J Am Chem Soc. 1982;104:3755-7.

47. Fu F, Wang Q, Ciganda R, Martinez-Villacorta AM, Escobar A, Moya S, Fouquet E, Ruiz J, Astruc D. Electron- and hydride-reservoir organometallics as precursors of catalytically efficient transition metal nanoparticles in water. Chem Eur J. 2018;24:6645-53.

48. Fu F, Ciganda R, Wang Q, Tabey A, Wang C, Escobar A, Martinez-Villacorta AM, Hernández R, Moya S, Fouquet E, Ruiz J, Astruc D. Cobaltocene Reduction of Cu and Ag Salts and Catalytic Behavior of the Nanoparticles Formed. ACS Catal. 2018;8:8100-6.

49. Wang W, Ciganda R, Wang C, Escobar A, Martinez-Villacorta AM, Ramirez M, Hernández R, Moya S, Ruiz J, Hamon J-R, Astruc D. Highly catalytically active 
Rh nanoparticles generated from cobaltocene and $\mathrm{RhCl}_{3}$ in aqueous solution. Inorg Chem Front. 2019;6:2704-8.

50. Glavee GN, Klabunde KJ, Sorensen CM. Hadjapanayis. Borohydride reductions of metal-ions - A new understanding of the chemistry leading to Nanoscale particles of metals, borides, and metal borates. Langmuir. 1992;8: 771-3.

51. Fu F, Martinez A, Escobar A, Irigoyen J, Moya S, Fouquet E, Ruiz J, Astruc D. Synthesis of late transition-metal nanoparticles by Na Naphthalenide reduction of salts and their catalytic efficiency. Inorg Chem Front. 2017;4: 2037-44.

52. Krause GH, Weis E. Chlorophyl fluorescence and photosynthesis: the basics. Annu Rev Pant Mol Biol. 1991;42:313-49.

53. Galloway JN, Dentener FJ, Capone DG. Nitrogen cycles: past, present, and future. Biogeochemistry. 2004;70:153-226.

54. Hunter BM, Gray HB, Muller AM. Earth-Abundant Water Oxidation Catalysts. Chem Rev. 2016;116:14120-36.

55. Poizot P, Laruelle S, Grugeon S, Dupont L, Tarascon J. Nano-sized transitionmetal oxides as negative-electrode materials for lithium-ion batteries. Nature. 2000;407:496-9.

56. Koper MTM. Thermodynamic theory of multi-Electron transfer reactions : implications for Electrocatalysis. J Electroanal Chem. 2011;660:254-60.

57. Bard AJ, Falkner LR. Electrochemical Methods. Fundamentals and Applications. 2nd ed. New York: Wiley; 2001.

58. Quinn BM, Liljeroth P, Ruiz V, Laaksonen T, Kontturi K. Electrochemical resolution of 15 oxidation states for monolayer protected gold nanoparticles. J Am Chem Soc. 2003;125:6644-5.

59. Daniel M-C, Astruc D. Gold nanoparticles : assembly, Supramolecular chemistry, quantum-size-related properties, and application toward biology, catalysis, and nanotechnology. Chem Rev. 2004;104:293-346.

60. Desbois MH, Astruc D, Guillin J, Varret F, Trautwein AX, Villeneuve G. Binuclear Electron-Reservoir Complexes- Syntheses, Reactivity, and Electronic Structure of the 37-Electron and 38-Electron Fulvalene Complexes $\left[\mathrm{Fe}_{2}\left(\mu_{2}, \eta^{10}-\mathrm{C}_{10} \mathrm{H}_{8} \text { (arene) }\right)_{2}\right]^{\mathrm{n}+}, \mathrm{n}=0$, 1. J Am Chem Soc 1989;111:5800-5809.

61. Lacoste M, Varret F, Toupet L, Astruc D. Orgagonodiiron Electron reservoir complexes containing a Polyaromatic ligand. Synthesis, stabilization, delocalized mixed Valencies and Intramolecular coupling. J Am Chem Soc 1987;109:6504-6.

62. Tulyathan B, Geiger WE. Structural consequences of Electron-transfer reactions. Multielectron processes involving structural changes- the 2electron reduction of $\mathrm{Os}_{6}(\mathrm{CO})_{18}$. J Am Chem Soc. 1985;107:5960-7.

63. Geiger WE, Connelly BG. The Electron-transfer reactions of Polynuclear Organotransition metal complexes. Advan Organometal. 1985;24:87-130

64. Huynh MHV, Meyer TJ. Proton-coupled Electron transfer. Chem Rev. 2007; 107:5004-64.

65. Warren JJ, Tronic TA, Mayer JM. Thermochemistry of proton-coupled Electron transfer reagents and its implications. Chem Rev. 2010;110:6961-7001.

66. Pannwitz A, Wenger OS. Proton-coupled multi-electron transfer and its relevance for artificial photosynthesis and photoredox catalysis. Chem Commun. 2019:55:4004-14.

67. Diallo AK, Daran J-C, Varret F, Ruiz J, Astruc D. How do redox groups behave around a rigid molecular platform? Hexa(ferrocenylethynyl)benzenes and their "electrostatic" redox chemistry. Angew Chem Int Ed. 2009;48: 3141-5

68. Diallo AK, Absalon C, Ruiz J, Astruc D. Ferrocenyl-terminated redox stars: synthesis and electrostatic effects in mixed-valence stabilization. J Am Chem Soc. 2011;133:629-41.

69. Flanagan JB, Margel S, Bard AJ, Anson FC. Electron-transfer to and from molecules containing multiple, noninteracting redox centerselectrochemical oxidation of poly(vinylferrocene). J Am Chem Soc. 1978;100: 4248-53.

70. Barrière $F$, Geiger WE. Use of weakly coordinating anions to develop an integrated approach to the tuning of $\Delta \mathrm{E}_{1 / 2}$ values by medium effects. J Am Chem Soc. 2006;128:3980-9.

71. Geiger WE, Barrière F. Organometallic electrochemistry based on electrolytes containing weakly-coordinating Fluoroarylborate anions. Acc Chem Res. 2010;43:1030-9.

72. Kahn O. Molecular Magnetism. VCH: New York, 1994; Chap. 10.5, pp $241-$ 245.

73. Chandrasekhar V, Nagendram S, Bansal S, Kosee MA, Powell DR. An Iron wheel on a tin drum: A novel assembly of a Hexaferrocene unit on a tinoxygen cluster. Angew Chem Int Ed. 2000;39:1833-5.
74. Inkpen MS, Scheerer S, Linseis M, White AJP, Winter RF, Albrecht T, Long NJ. Oligomeric ferrocene rings. Nat Chem. 2016;8:825-30.

75. Herbert DE, Gilroy JB, Chan WY, Chabanne L, Staubitz A, Lough AJ, Manners I. Redox-active Metallomacrocycles and cyclic Metallopolymers: Photocontrolled ring-opening Oligomerization and polymerization of silicon-bridged [1]Ferrocenophanes using Substitutionally-labile Lewis bases as initiators. J Am Chem Soc. 2009;131:14958-68.

76. Ngyuen P, Gomez-Elipe P, Manners I. Organometallic polymers with transition metals in the main chain. Chem Rev. 1999:99:1515-48.

77. Manners I. Materials science- putting metals into polymers. Science. 2001; 294:1664-6.

78. Abd-El-Aziz AS, Strohm EA. Transition-metal containing macromolecules: en route to new functional materials. Polymer. 2010;53:4879-921.

79. Pietschnig R. Polymers with pendant ferrocenes. Chem Soc Rev. 2016;45:5216-31.

80. Special issue: Controlled Radical Polymerizations dedicated to Krzysztof Matyjaszewski at the occasion of his Wolf Prize. Isr J Chem. 2012:52:197-314.

81. Rulkens R, Lough AJ, Manners I, Lovelace SR, Grant C, Geiger WE. Linear oligo(ferrocenyldimethylsilanes) with between two and nine ferrocene units: electrochemical and structural models for poly(ferrocenylsilane) high polymers. J Am Chem Soc. 1996;118:12683-95.

82. Tanford C in "The Physical Chemistry of Macromolecules" Wiley, New York, N.Y., 1961, p. 362.

83. Saji T, Pasch NF, Webber SE, Bard AJ. Electrochemical behavior of polymers in aprotic media. Polyvinylnaphthalenene and polyvinylanthracene. J Phys Chem. 1978:82:1101-5.

84. Schrock RR. Living ring-opening metathesis polymerization catalyzed by well-characterized transition-metal Alkylidene complexes. Acc Chem Res. 1990;23:158-65.

85. Buchmeiser MR. Homogeneous metathesis polymerization by well-defined Group VI and Group VIII transition-metal Alkylidenes: fundamentals and applications in the preparation of advanced materials. Chem Rev. 2000;100: 1565-604.

86. Bielawski CW, Grubbs RH. Living ring-opening methathesis polymerization. Prog Polym Sci. 2008;33:759-85.

87. Deraedt C, d'Halluin M, Astruc D. Metathesis reactions: recent trends and challenges. Eur J Inorg Chem. 2013:4881-908.

88. Knall A-C, Slugovc C, in Olefin Metathesis - Theory and Practice (Ed.: K. Grela), Wiley, Hoboken, 2014, pp. 269-284.

89. Sanford MS, Love JA, Grubbs RH. A versatile precursor for the synthesis of new ruthenium olefin metathesis catalysts. Organometallics. 2001:20:5314-8.

90. Vougioukalakis GC, Grubbs RH. Ruthenium-based heterocyclic Carbenecoordinated olefin metathesis catalysts. Chem Rev. 2010;110:1746-87.

91. Abd-El-Aziz AS, Agatemor C, Etkin N. Sandwich complex-containing macromolecules: property Tunability through versatile synthesis. Macromol Rapid Commun. 2014;35:513-59.

92. Hardy CG, Zhang J, Yan Y, Ren L, Tang C. Metallopolymers with transition metals in the side-chain by living and controlled polymerization techniques. Prog Polym Sci. 2014;39:1742-96.

93. Zha Y, Thaker HD, Maddikeri RR, Gido SP, Tuominen MT, Tew GN. Nanostructured block-random copolymers with tunable magnetic properties. J Am Chem Soc. 2012;134:14534-41.

94. Ren L, Zhang J, Bai X, Hardy CG, Shimizu KD, Tang C. Preparation of cationic cobaltocenium polymers and block copolymers by "living" ring-opening metathesis polymerization. Chem Sci. 2012;3:580-3.

95. Gu H, Rapakousiou A, Castel P, Guidolin N, Pinaud N, Ruiz J, Astruc D. Living ring-opening metathesis-polymerization synthesis and redox-sensing properties of Norbornene polymers and copolymers containing Ferrocenyl and Tetraethylene glycol groups. Organometallics. 2014;33:4323-35.

96. Rapakousiou A, Deraedt C, Gu H, Salmon L, Belin C, Ruiz J, Astruc D. MixedValent click intertwined polymer units containing Biferrocenium chloride side chains form Nanosnakes that encapsulate gold nanoparticles. J Am Chem Soc. 2014;136:13995-8.

97. Gu H, Ciganda R, Hernández R, Castel P, Zhao P, Ruiz J, Astruc D. ROMP synthesis and redox properties of Polycationic Metallopolymers containing the Electron-reservoir complex $\left[\mathrm{Fe}\left(\eta^{5}-\mathrm{C}_{5} \mathrm{H}_{5}\right)\left(\eta^{6}-\mathrm{C}_{6} \mathrm{Me}_{6}\right)\right]\left[\mathrm{PF}_{6}\right]$ Macromolecules. 2015:48:6071-6.

98. Gu H, Ciganda R, Castel P, Vax A, Gregurec D, Irigoyen J, Moya S, Salmon L, Zhao P, Ruiz J, Hernández R, Astruc D. Redox-robust Pentamethylferrocene polymers and Supramolecular polymers and controlled self-assembly of Pentamethylferricenium polymer-embedded Ag, Agl and au nanoparticles. Chem Eur J. 2015;21:18177-86. 
99. Gu H, Ciganda R, Hernández R, Castel P, Vax A, Zhao P, Ruiz J, Astruc D. Diblock Metallocopolymers containing various Iron Sandwich complexes: living ROMP synthesis and selective reversible oxidation. Polym Chem. 2016; 7:2358-71.

100. Gu HB, Ciganda R, Castel P, Ruiz J, Astruc D. Living ROMP Syntheses and redox properties of Triblock Metallocopolymer redox cascades. Macromolecules. 2016;49:4763-73.

101. Dragutan I, Dragutan V, Siminescu B, Demonceau A, Fischer H. Recent advances in metathesis-derived polymers containing transition metals in the side chain. Beilstein J Org Chem. 2015;11:2747-62.

102. Dragutan I, Dragutan V, Filip P, Simionescu BC, Demonceau A. ROMP synthesis of Iron-containing organometallic polymers. Molecules. 2016;21: 198.

103. Gu HB, Ciganda R, Castel P, Ruiz J, Astruc D Living ROMP Synthesis and Redox Properties of Triblock Metallocopolymers Containing Side-Chain Iron and Cobalt Sandwich Complexes Macromol Chem Phys 2018;219:1800384.

104. Qiu GR, Liu X, Wang BR, Gu HB, Wang WX. Ferrocene-Containing Amphiphilic Polynorbornenes as Biocompatible Drug Carriers. Polym Chem. 2019;10:2527-39.

105. Mu SD, Liu WT, Zhao L, Long YR, Gu HB. Antimicrobial AgNPs composites of gelatin hydrogels Crosslinked by Ferrocene-containing Tetrablock Terpolymer. Polymer. 2019;169:80-94.

106. Liu X, Liu FF, Astruc D, Lin W, Gu HB. Highly-branched amphiphilic organometallic dendronized diblock copolymer: ROMP synthesis, selfassembly and long-term au and Ag nanoparticle stabilizer for highefficiency catalysis. Polymer. 2019;173:1-10.

107. Long YR, Song B, Shi CT, Liu WT, Gu H B AuNPs composites of gelatin hydrogels crosslinked by ferrocene-containing polymer as recyclable supported catalysts J Appl Polym Sci 2020;137:48653.

108. Ciganda R, Gu H, Castel P, Zhao P, Ruiz J, Hernández R, Astruc D. ROMP synthesis and redox properties of Polycationic Metallopolymers containing the Electron-reservoir complex $\left[\mathrm{Fe}\left(\eta^{5}-\mathrm{C}_{5} \mathrm{H}_{5}\right)\left(\eta^{6}-\mathrm{C}_{6} \mathrm{Me}_{6}\right)\right]\left[\mathrm{PF}_{6}\right]$. Macromol Rapid Commun. 2016;37:105-11.

109. Gu HB, Ciganda R, Castel P, Moya S, Hernandez R, Ruiz J, Astruc D. Tetrablock Metallopolymer Electrochromes. Angew Chem-Int Ed. 2018;57: 2204-8.

110. Ciganda R, Irigoyen J, Gregurec D, Hernández R, Moya S, Wang C, Ruiz J, Astruc D. Liquid-liquid interfacial Electron transfer from Ferrocene to au(III): an ultra-simple and fast au nanoparticle synthesis in water under ambient conditions. Inorg Chem. 2016;55:6361-3.

111. Ciganda R, Gu H, Hernández R, Escobar A, Martínez A, Yate L, Moya S, Ruiz J, Astruc D. Electrostatic assembly and stabilization of functional and macromolecular Ferricinium-stabilized gold nanoparticles. Inorg Chem. 2017;56:2784-91.

112. Haruta M. Gold as a novel catalyst in the 21 rst century : preparation, working mechanism and applications. Gold Bull. 2002;37:27-36.

113. Rai M, Yadav A, Gade A. Silver nanoparticles as a new generation of antimicrobiols. Biotechnol Adv. 2009;27:76-83.

114. Zhao P, Feng X, Huang D, Yang G, Astruc D. Basic concepts and recent advances in Nitrophenol reduction by gold- and other transition metal nanoparticles. Coord Chem Rev. 2015;287:114-36.

115. Tomalia DA, Naylor AM, Goddard W III. Starburst Dendrimers: molecularlevel control of size, shape, surface chemistry, topology, and flexibility from atoms to macroscopic matter. Angew Chem, Int Ed Engl. 1990;29:138-75.

116. Newkome GR, Moorefield CN. Building blocks for dendritic polymers. Aldrichim Acta. 1992;25:31-8.

117. Zeng SW, Zimmerman SC. Dendrimers in supramolecular chemistry : from molecular recognition self-assembly. Chem Rev. 1997;97:1681-712.

118. Grayson SM, Fréchet JMJ. Convergent dendrons and dendrimers: from synthesis to applications. Chem Rev. 2002;102:3819-67.

119. Astruc D, Boisselier E, Ornelas C. Dendrimers designed for functions: from physical, photophysical, and supramolecular properties to applications in sensing, catalysis, molecular electronics, photonics, and nanomedicine. Chem Rev. 2010;110:1857-959.

120. Balzani V, Campana S, Denti G, Jris A, Serroni S, Venturi M. Designing dendrimers based on transition metal complexes. Light-harvesting properties and predetermined redox patterns. Acc Chem Res. 1998;31:26-34.

121. Gorman C. Metallodendrimers: structural diversity and functional behavior. Adv Mater. 1998;10:295-309.

122. Newkome GR, He E, Moorefield CN. Dendrimers derived from 1 -> 3 branching motifs. Chem Rev. 1999;99:1689-746.
123. Bosman AW, Janssen HM, Meijer EW. About dendrimers: structure, physical properties, and applications. Chem Rev. 1999;99:1665-88.

124. Astruc D, Chardac F. Dendritic catalysts and Dendrimers in catalysis. Chem Rev. 2001;101:2991-3024.

125. Van Heerbeck R, Kamer PCJ, van Leeuwen PWNM, Reek JNH. Dendrimers as support for recoverable catalysts and reagents. Chem Rev. 2002;102:3717-56.

126. Newkome GR, Moorefiels CN, Chakraborty S. A Long pathway to the quantitative assembly of Metallodendrimers. J Inorg Organomet Chem Mater. 2018;28:360-8.

127. Casado CM, Cuadrado I, Moran M, Alonso B, Garcia B, Gonzales B, Losada J. Redox-active ferrocenyl dendrimers and polymers in solution and immobilised on electrode surfaces. Coord Chem Rev. 1999;185-186:53-79.

128. Casado CM, Alonso B, Losada, Garcia-Armada MPC. Redox-Active organometallic dendrimers as electrochemical redox sensors in Designing Dendrimers, Campagna S, Ceroni P, Puntoriero F. eds. Wiley, Hoboken, 2012 pp. 219-262.

129. Astruc D, Valério C, Fillaut J-L, Ruiz J, Hamon JR, Varret F. Electron-Reservoir Sandwich Complexes: From Mono- and Bimetallic Complexes to Molecular Trees "Supramolecular Magnetism" Kahn, O. Ed. NATO ASAI Séries, Kluwer, Dordrecht. 1996:107-127.

130. Valério C, Fillaut J-L, Ruiz J, Guittard J, Blais J-C, Astruc D. The dendritic effect in molecular recognition: Ferrocene Dendrimers and their use as Supramolecular redox sensors for the recognition of small inorganic anions. J Am Chem Soc. 1997;119:2588-9.

131. Valério C, Alonso E, Ruiz J, Blais J-C, Astruc D. A Polycationic Metallodendrimer with 24 Organoiron termini which senses chloride and bromide anions. Angew Chem Int Ed Engl. 1999;38:1747-51.

132. Labande A, Ruiz J, Astruc D. Supramolecular gold nanoparticles for the redox recognition of Oxoanions : syntheses, titrations, Stereoelectronic Efects, and selectivity. J Am Chem Soc. 2002;124:1782-9.

133. Daniel M-C, Ruiz J, Nlate S, Blais J-C, Astruc D. Nanoscopic assemblies between Supramolecular redox active Metallodendrons and gold nanoparticles: syntheses, characterization and selective recognition of $\mathrm{H}_{2} \mathrm{PO}_{4}{ }^{-}, \mathrm{HSO}_{4}{ }^{-}$and Adenosine-5'-triphosphate (ATP ${ }^{2-}$ ) anions. J Am Chem Soc. 2003;125:2617-28.

134. Daniel M-C, Ruiz J, Astruc D. Supramolecular H-bonded assemblies of redoxactive Metallodendrimers and positive and unusual dendritic effects on the recognition of $\mathrm{H}_{2} \mathrm{PO}_{4}^{-}$. J Am Chem Soc. 2003;125:1150-1.

135. Moulines F, Astruc D. Tentacled Iron Sandwichs. Angew Chem, Int Ed Engl. 1988:27:1347-9.

136. Moulines F, Djakovitch L, Boese R, Gloaguen B, Thiel W, Fillaut J-L, Delville $\mathrm{M}-\mathrm{H}$, Astruc D. Organometallic molecular trees as multi-Electron and proton reservoirs: $\mathrm{CpFe}^{+}$induced Nona-Allylation of Mesitylene and phase-transfer catalyzed synthesis of a redox active Nona-Iron complex. Angew Chem, Int Ed Engl. 1993;32:1075-7.

137. Sartor V, Djakovitch L, Fillaut J-L, Moulines F, Neveu F, Marvaud V, Guittard J, Blais J-C, Astruc D. Organoiron routes to a new Dendron for fast dendritic syntheses using divergent and convergent methods. J Am Chem Soc. 1999; 121:2929-30.

138. Ruiz J, Lafuente G, Marcen S, Ornelas C, Lazare S, Cloutet E, Blais J-C, Astruc D. Construction of Giant Dendrimers using a Tripodal Buiding block. J Am Chem Soc. 2003;125:7250-7.

139. Newkome GR, Yao ZQ, Bager GR, Gupta VK. Micelles 1. Cascade moleculesA new approach to micelles- A [27]- arborol. J Org Chem. 1985;50:2003-4.

140. Newkome GR, Shreiner $C$. Dendrimers derived from $1 \rightarrow 3$ branching motifs. Chem Rev. 2010;110:6338-442.

141. Nlate S, Ruiz J, Blais J-C, Astruc D. Ferrocenylsilylation of dendrons: a fast convergent route to redox- stable ferrocene dendrimers. Chem Commun. 2000:417-8.

142. Badeche S, Daran J-C, Ruiz J, Astruc D. Synthesis and coordination chemistry of ferrocenyl-1,2,3-triazolyl ligands. Inorg Chem. 2008;47:4903-8.

143. Daniel MC, Ruiz J, Blais J-C, Astruc D. Synthesis of five generations of redoxstable pentamethylamidoferrocenyl dendrimers and comparison of amidoferrocenyl- and pentamethylamidoferrocenyl dendrimers as electrochemical exoreceptors for the selective recognition of $\mathrm{H}_{2} \mathrm{PO}_{4}^{-}$, $\mathrm{HSO}_{4}{ }^{-}$, and adenosine 5 '-triphosphate (ATP) anions: Stereoelectronic and hydrophobic roles of cyclopentadienyl permethylation. Chem Eur J. 2003;9: 4371-9.

144. Ornelas C, Ruiz J, Cloutet E, Alves S, Astruc D. Click assembly of 1,2,3Triazole-linked Dendrimers including Ferrocenyl Dendrimers that sense both Oxo-anions and metal Cations. Angew Chem Int Ed. 2007;46:872-7. 
145. Djeda R, Rapakousiou A, Liang L, Guidolin N, Ruiz J, Astruc D. Click Syntheses of Large 1,2,3-Triazolylbiferrocenyl Dendrimers and Selective Roles of the Inner and Outer Ferrocenyl Groups in the Redox Recognition of the ATP2- Anion and Pd" Cation. Angew Chem, Int Ed. 2010;49:8152-6.

146. Rapakousiou A, Wang Y, Belin C, Pinaud N, Ruiz J, Astruc D. "Click" Synthesis and Redox Properties of Triazolyl Cobalticinium Dendrimers Inorg Chem 2013;52:6685-6693.

147. Wang A, Ornelas C, Astruc D, Hapiot P. Electronic communication between immobilized Ferrocenyl Dendrimers. J Am Chem Soc. 2009;131:6652-3.

148. Lhenry S, Jalkh J, Leroux YR, Ruiz J, Ciganda R, Astruc D, Hapiot P. Tunnelling Dendrimers. Enhancing charge transport through insulating layer using redox molecular objects. J Am Chem Soc. 2014;136:17950-3.

149. Vilà N, André E, Ciganda R, Ruiz J, Astruc D, Walcarius A. Molecular sieving with vertically aligned Mesoporous silica films and electronic wiring through isolating Nanochannels. Chem Mater. 2016;28:2511-4.

150. Ornelas C, Ruiz J, Belin C, Astruc D. Giant dendritic molecular Electrochrome batteries with Ferrocenyl and Pentamethylferrocenyl termini. J Am Chem Soc. 2009;131:590-601.

151. Park KS, Schougaard SB, J B Goodenough Conducting-Polymer/Iron-RedoxCouple Composite Cathodes for Lithium Secondary Batteries Adv Mater 2007;19:848.

152. Beladi-Mousavi SM, Sadaf S, Walder L, Gallei M, Rüttiger C, Eigler S, Halbig CE. Poly(vinylferrocene)-reduced Graphene oxide as a high power/high capacity Cathodic battery material. Adv En Mater. 2016;6:1600108.

153. Wu XY, Xu YK, Zhang C, Leonard DP, Markr LJ, Ji XL. Reverse dual-ion battery via a $\mathrm{ZnCl}_{2}$ water-in-salt electrolyte. J Am Chem Soc. 2019;141:6338-44.

154. Astruc D. Research avenues on dendrimers towards molecular biology: From biomimetism to medicinal engineering. CR Acad Sci Ser 2, 1996;322: 757-766.

155. Ornelas C. Application of ferrocene and its derivatives in cancer research. New J Chem. 2011;35:1973-85.

156. Gu HB, Mu SD, Qiu GR, Liu X, Zhang L, Yuan YF, Astruc D. Redox-stimuliresponsive drug delivery systems with supramolecular ferrocenyl-containing polymers for controlled release. Coord Chem Rev. 2018;364:51-85.

157. Li N, Zhao P, Igartua ME, Rapakousiou A, Salmon L, Moya S, Ruiz J, Astruc D. Stabilization of AuNPs by Monofunctional Triazole linked to Ferrocene, Ferricenium or Coumarin and applications to synthesis, sensing and catalysis. Inorg Chem. 2014;53:11802-8.

158. Wang Q, Fu F, Martinez-Villacorta AM, Moya S, Salmon L, Vax A, Hunel J, Ruiz J, Astruc D. Electron flow in large metallomacromolecules and electronic switch of nanoparticle stabilization: new click ferrocenyl dentromers that reduce au(III) to au nanoparticles. Chem Eur J. 2018;24: 12686-94.

159. Wang Y, Salmon L, Ruiz J, Astruc D. Metallodendrimers in three oxidation states with electronically interacting metals and stabilization of size-selected gold nanoparticles. Nat Commun. 2014;5:3489.

160. Boisselier E, Diallo AK, Salmon L, Ornelas C, Ruiz J, Astruc D. Encapsulation and stabilization of gold nanoparticles with "click" Polyethyleneglycol Dendrimers. J Am Chem Soc. 2010;132:2729-42.

161. Deraedt C, Rapakousiou A, Wang Y, Salmon L, Bousquet M, Astruc D. Multifunction redox polymers: Electrochrome, polyelectrolyte, sensor, electrode modifier, nanoparticle stabilizer and catalyst template. Angew Chem. Int Ed. 2014;53:8445-9.

162. Zhao L, Ling QJ, Liu X, Hang CD, Zhao QX, Liu FF, Gu HB. Multifunctional triazolylferrocenyl Janus dendron: Nanoparticle stabilizer, smart drug carrier and supramolecular nanoreactor. Appl Organomet Chem. 2018;32:e4000.

163. Liu X, Lin W, Astruc D, Gu HB. Syntheses and applications of Dendronized polymers. Progr Polym Sci. 2019;96:43-105.

164. Liu FF, Liu X, Astruc D, Gu HB. Dendronized triazolyl-containing ferrocenyl polymers as stabilizers of gold nanoparticles for recyclable two-phase reduction of 4-nitrophenol. J Coll Interface Sci. 2019;533:161-70.

165. Liu X, Liu FF, Wang YL, Gu HB. Ferrocene-containing amphiphilic dendronized random copolymers as efficient stabilizers for reusable gold nanoparticle catalysts. React Funct Polym. 2019;143:104325.

166. Liu X, Mu SD, Long YR, Qiu GR, Ling QJ, Gu HB, Lin W. Gold nanoparticles stabilized by 1,2,3-Triazolyl Dendronized polymers as highly efficient Nanoreactors for the reduction of 4-Nitrophenol. Catal Letters. 2019;149: 544-51

167. Liu X, Qiu GR, Zhang L, Liu FF, Um SD, Long YR, Zhao QX, Liu Y, Gu HB. Controlled ROMP Synthesis of Ferrocene-Containing Amphiphilic
Dendronized Diblock Copolymers as Redox-Controlled Polymer Carriers. Macromol Chem Phys. 2018;219:1800273.

168. Herves P, Perez-Lorenzo M, Liz-Marzan LM, Dzubiella J, Lu Y, Ballauff M. Catalysis by metallic nanoparticles in aqueous solution: model reactions. Chem Soc Rev. 2012;41:5577-87.

169. Aditya T, Pal A, Pal T. Nitroarene reduction: a trusted model reaction to test nanoparticle catalysts. Chem Commun. 2015;51:9410-31.

170. Crooks RM, Zhao M, Sun L, Chechik V, Yeung LK. Dendrimer-encapsulated metal nanoparticles: synthesis, characterization, and applications to catalysis. Acc Chem Res. 2001;34:181-90.

171. Astruc D, Heuze K, Gatard S, Méry D, Nlate S, Plault L. Metallodendritic catalysis for redox and C-C bond formation reactions: A step towards Green chemistry. Advan Syn Catal. 2005;347:329-38.

172. Ornelas C, Salmon L, Ruiz J, Astruc D. Catalytically Efficient Palladium Nanoparticles Stabilized by Click Ferrocenyl Dendrimers. Chem. Commun. 2007, 4946-4948.

173. Astruc D. Palladium catalysis using dendrimers : molecular catalysts versus nanoparticles. Tetrahedron-Asym. 2010;21:1041-54.

174. Deraedt C, Astruc D. "Homeopathic" Palladium Nanoparticle Catalysis of Cross Carbon-Carbon Coupling Reactions Acc Chem Res 2014;47:494-503.

175. Liu X, Gregurec D, Irigoyen J, Martinez A, Moya S, Ciganda R, Hermange P, Ruiz J, Astruc D. Precise localization of metal nanoparticles in Dendrimer Nanosnakes or inner periphery and consequences in catalysis. Nat Commun. 2016;7:13152.

176. Dempsey JL, Winkler JR, Gray HB. Proton-coupled electron flow in protein redox machines. Chem Rev. 2010;110:7024-39.

177. Sharma AK, Kim M, Cameron CS, Lyndon M, Gorman CB. Dendritically encapsulated, water-soluble Fe(4)S(4) : synthesis and electrochemical properties. Inorg Chem. 2010;49:5072-8.

178. Kaifer AE. Electron transfer and molecular recognition in metallocenecontaining dendrimers. Eur J Inorg Chem. 2007:5015-27.

179. Astruc D. Introduction: nanoparticles in catalysis. Chem Rev. 2020;120:461-3.

180. Kandel ER, Schwartz JH, Jessell TM. Principles of neuronal science 4th edn (McGraw-hill, 2000).

181. Rosen BM, Wilson CJ, Wilson DA, Peterca M, Imam MR, Percec V. Dendronmediated self-assembly, disassembly, and self-organization of complex systems. Chem Rev. 2009;109:6275-340.

182. Hailes RLN, Oliver AM, Gwyther J, Whittell GR, Manners I. Polyferrocenylsilanes: synthesis, properties, and applications. Chem Soc Rev. 2016;45:5358-407

183. Whitesides GM, Grybowski B. Self-assembly at all scales. Science. 2002;295: 2418-21.

184. Beer PD, Gale PA. Anion recognition and sensing: the state of the art and future perspectives. Angew Chem Int Ed. 2001:40:486-516.

185. Rutiger C, Gemmer L, Schottner S, Kuttich B, Stuhn B. Gallei. Preparation and self-assembly of polyferrocenyldimethylsilane-containing tri- and pentablock terpolymers. J Organomet Chem. 2019;882:80-9.

186. Sakamoto R, Wu K-H, Matsuoka R, Maeda H, Nishihara H. m-Conjugated bis(terpyridine)metal complex molecular wires. Chem Soc Rev. 2015;44: 7698-714.

187. Chakraborty S, Newkome GR. Terpyridine-based metallosupramolecular constructs: tailored monomers to precise 2D-motifs and 3D-metallocages. Chem Soc Rev. 2018;47:3991-4016

188. Yamamoto K, Imaoka T. Precision synthesis of subnanoparticles using Dendrimers as a Superatom synthesizer. Acc Chem Res. 2014;47:1127-36.

189. Yamamoto K, Imaoka T, Tanabe M, Kambe T. New horizon of nanoparticle and cluster catalysis with Dendrimers. Chem Rev. 2020;120:1397-437.

190. Hein R, Beer PD, Davies JJ. Electrochemical anion sensing: Supramolecular approaches. Chem Rev. 2020:120:1888-935.

\section{Publisher's Note}

Springer Nature remains neutral with regard to jurisdictional claims in published maps and institutional affiliations. 